\title{
Effect of creep temperature on Z-phase formation in heat-resistant $9 \%$ Cr-3\% Co martensitic steel
}

\author{
A. Fedoseeva *, I. Nikitin, N. Dudova, R. Kaibyshev \\ Belgorod National Research University, Pobeda 85, Belgorod, 308015, Russia
}

\section{A R T I C L E I N F O}

\section{Keywords:}

Characterization

Electron microscopy

Stress/strain measurements

Iron alloys

Plasticity methods

Phase transformation

\begin{abstract}
A B S T R A C T
The Z-phase (CrVN) precipitation in a 9\% Cr-3\% Co martensitic steel during creep at $923 \mathrm{~K}$ and $948 \mathrm{~K}$ has been investigated with aim to establish the effect of temperature on the nucleation mechanism of these particles and their coarsening behavior. Ostwald ripening of VX carbonitrides strongly affects these processes. An increase in creep temperature significantly accelerates the transformation of the nanoscale MX carbonitrides into the Zphase particles causing the Z-phase nucleation in a shorter time. Two different mechanisms of the Z-phase precipitation have been observed. Firstly, for creep tests at $923 \mathrm{~K}$ and $948 \mathrm{~K}$ with creep rupture time longer than $2000 \mathrm{~h}$, the formation of the stable Z-phase particles with a tetragonal lattice occurs through in-situ transformation of a cubic lattice of the MX carbonitrides leading to a continuous flux of $\mathrm{Cr}$ atoms from the ferritic matrix into these particles. The coarsening Z-phase occurs at the expense of dissolution of VX carbonitrides. Secondly, for creep test at $948 \mathrm{~K}$ with duration of $773 \mathrm{~h}$, the strain-induced metastable Z-phase with the cubic lattice nucleates on the V-rich $\mathrm{MX} /$ ferrite interfaces with following transformation into the stable Z-phase with the tetragonal lattice under creep testing with longer duration. Concurrently, extensive coarsening Cr-rich VX carbonitrides occurs independently. As a result, coarsening Z-phase leads to insignificant dissolution of VX carbonitrides. The creep strength breakdown appearance is not related to the formation and/or coarsening of the Z-phase at both temperatures.
\end{abstract}

\section{Introduction}

Nine to $12 \% \mathrm{Cr}$ martensitic steels are used as materials for main steam pipe lines, tubes of boiler superheaters in the fossil-fired power plants operating at a steam temperature ranging from 853 to $873 \mathrm{~K}$ and a steam pressure of 250 bar [1-4]. The use of these materials for ultra-supercritical (USC) power plants with a steam temperature $\geq 873 \mathrm{~K}$ and a steam pressure $\geq 250$ bar is limited by microstructural instability of these steels [1-3,5]. Improvement of the creep strength of the $9-12 \%$ Cr steels is attained by modification of their chemical composition by addition of Co [1,2,4-11], which hinders the coarsening of the boundary particles and climb of the lattice dislocations $[1,4,6,12]$. The modification of P92 steel by $3 \mathrm{wt} \%$ Co enhanced the creep resistance at $923 \mathrm{~K}$ from $72 \mathrm{MPa}$ [13] to $85 \mathrm{MPa}[6,14]$ predicted through the Larson-Miller parameter.

The MX carbonitrides play a crucial role in superior creep strength of the $9-12 \% \mathrm{Cr}$ steels precipitating within ferritic matrix during heat treatment and contributing to the dispersion hardening and stability of the tempered martensite lath structure (TMLS) under exploitation conditions [1,15-20]. The MX carbonitride has a face-centered cubic lattice with a parameter ranging from 0.4139 to $0.4470 \mathrm{~nm}$ depending on the chemical composition [1,5]. However, MX carbonitride is an unstable phase and should be replaced by the stable Z-phase $(\mathrm{Cr}(\mathrm{V}, \mathrm{Nb})$ $\mathrm{N}$ ) during long-term exposure in the temperature range of 873-973 K [15-41]. The disappearance of the fine MX carbonitrides can lead to recovery of the TMLS in the vicinity of prior austenite grain boundaries that abruptly drops the creep strength $[16,18,19,22,30]$.

There is a distinct difference between kinetics, driving forces, and transformation mechanisms of the $\mathrm{MX} \rightarrow \mathrm{Z}$-phase transformation in the 9\% $\mathrm{Cr}$ and $11-12 \% \mathrm{Cr}$ steels [6,9,16-19,23,29-31,37,41-43]. The formation of Z-phase results in the creep strength breakdown appearance in the $11-12 \%$ Cr steels $[16,18,19,33,35,36,42]$. In contrast, this transformation is unimportant for the creep strength breakdown in the $9 \% \mathrm{Cr}$ steels [1-6,16-19,34,37,42]. A decrease in the creep strength with increasing rupture time is attributed to the evolution of other secondary phase particles in these materials [1-6,16-19,44,45].

Two types of the Z-phase were revealed in the 9-12\% Cr steels: (1) the metastable Z-phase having a face-centered cubic lattice with a

\footnotetext{
* Corresponding author.

E-mail address: fedoseeva@bsu.edu.ru (A. Fedoseeva).
} 
parameter of $0.404 \mathrm{~nm}$ and (2) the stable Z-phase having a tetragonal distortion of body-centered cubic lattice with double layers of similar atoms alternating along the $c$ axis to give an ... AABBAABB ... sequence [23-25,31,36-39]. The Z-phase particles negatively affect the creep strength if the size of these particles is significantly larger than that of the MX carbonitrides that leads to the increase in the inter-particle spacing of the Z-phase and elimination of the dispersion hardening due to these particles $[16,17,35,40]$. The interface between the coarse Z-phase and the matrix can serve as a nucleation site of creep void [18]. Strain and/or stress stimulate the Z-phase precipitation during creep and/or ageing exposure [16,37]. However, if the sizes of the Z-phase and MX carbonitrides are comparable, the Z-phase particles can positively affect the creep strength as MX carbonitrides [5,12,18,19,30-32,37,41].

Two types of the nucleation mechanisms were reported for the Zphase particles in the $9-12 \%$ Cr steels [23-25,28-31,35,38,39,41]. The first type of the nucleation mechanism is the Z-phase formation through in situ transformation of the face-centered cubic crystal lattice of MX carbonitrides [23-25,28-31,33,37-39]. This nucleation mechanism is the main mechanism of the Z-phase formation, which is observed in the $11-12 \%$ Cr steels, and leads to the formation of the coarse particles of this phase [23,26-33,35,37]. The second type of the nucleation mechanism is the nucleation on the surface of the primary NbX carbonitrides $[23,28-31,35]$ or the secondary VX carbonitrides [37]. This nucleation mechanism of the Z-phase is rarely observed and usually leads to the formation of the nanoscale Z-phase particles [23,28-31,35,37]. Moreover, the nucleation mechanism of the Z-phase depends on the Cr content $[29,30,33]$; strain and/or stress can also change the nucleation mechanism during creep and/or ageing exposure [37]. Superposition of these nucleation mechanisms can lead to avalanche-like growth of the Z-phase particles [37]. Creep and/or ageing temperature as well as $\mathrm{Cr}$ content determine the coarsening rate of Z-phase and dissolution of MX carbonitrides [29,30]. In the previous study [37], we considered the effect of strain on the precipitation of Z-phase in the Co-modified $9 \% \mathrm{Cr}$ steel. In the present work, we will pay attention to the effect of creep temperature on the nucleation mechanism and coarsening behavior of the Z-phase particles. Thermodynamics and kinetics of the Z-phase nucleation and growth will be considered in details to provide a deep insight to the role of this phase in the creep resistance of the high $\mathrm{Cr}$ steels.

\section{Experimental}

A 3 wt $\%$ Co-modified P92-type steel ( $9 \% \mathrm{Cr}-3 \% \mathrm{Co}$ ) with chemical composition (in $\mathrm{wt}_{\mathrm{t}} \%$ ) of $\mathrm{Fe}$ (bal.)-0.12C-9.5Cr-3.2Co-2.0W$0.45 \mathrm{Mo}-0.06 \mathrm{Si}-0.2 \mathrm{Mn}-0.1 \mathrm{Ni}-0.2 \mathrm{~V}-0.06 \mathrm{Nb}-0.05 \mathrm{~N}-0.005 \mathrm{~B}$ was prepared by air melting. Square bars with a $13 \times 13 \mathrm{~mm}^{2}$ cross-section were hot forged in the temperature range from $1423 \mathrm{~K}$ to $1173 \mathrm{~K}$. This steel was subjected to solution treatment at $1323 \mathrm{~K}$ for $30 \mathrm{~min}$, air cooled, followed by normalizing and finally tempered at $1023 \mathrm{~K}$ for $3 \mathrm{~h}$. Flat specimens with a $25 \mathrm{~mm}$ gage length and a $7 \times 3 \mathrm{~mm}^{2}$ cross section were crept until rupture at $923 \mathrm{~K}$ under the applied stresses of 140, 160 and $180 \mathrm{MPa}$ and at $948 \mathrm{~K}$ under the applied stresses ranging from 80 to 180 MPa with a step of $20 \mathrm{MPa}$. Cylindrical specimens with a $100 \mathrm{~mm}$ gage length and a $10 \mathrm{~mm}$ diameter were crept until rupture at $923 \mathrm{~K}$ under the applied stresses of 120 and $100 \mathrm{MPa}$.

The structural investigations were carried out in the portions of gauge length with uniform elongation of the crept specimens. The microstructural characterization was performed using a JEM-2100 transmission electron microscope (TEM) equipped with an INCA energy dispersive X-ray spectroscope (EDS). The TEM specimens were prepared by electro-polishing at room temperature using a solution of $10 \%$ perchloric acid in glacial acetic acid with Struers Tenupol-5 polisher. In addition, carbon extraction replicas were used to clarify the chemical composition of dispersoids to avoid matrix effects when obtaining EDS spectra. Before replication, the specimen surface was mechanically polished followed by etching with a solution of $10 \%$ hydrochloric acid in ethanol. The size distribution and mean radius of the secondary phase particles were estimated by counting at least 50 particles on at least 6 arbitrarily selected typical TEM images for each data point. The precipitates were identified by a concurrent analysis of the EDS measurements and electron diffraction patterns. The particle coarsening kinetic was calculated using Prisma-software on the base of Calphad Database Calculation with the kinetic MOBFE1 and thermodynamic TCFE6 databases. The time dependencies of the mean radius were determined for MX carbonitride (FCC) and CrVN particles assuming the simultaneous growth of these phases; dislocations acted as a nucleation site. Other details of structural characterization and specimen preparation were reported previously [6,12,46-51].

\section{Results}

\subsection{MX carbonitrides after tempering}

Microstructural characteristics of the $9 \% \mathrm{Cr}-3 \%$ Co steel were reported in the previous works in detail $[6,34,37,50,51]$. In the present study, we summarized the most important features of TMLS. The mean transverse size of the martensitic laths was about $400 \mathrm{~nm}$. High dislocation density of $2 \times 10^{14} \mathrm{~m}^{-2}$ was observed within the martensitic laths. The round Cr-rich $\mathrm{M}_{23} \mathrm{C}_{6}$ carbides with a mean size of $90 \mathrm{~nm}$ decorated the high-angle boundaries of prior austenite grains, block and packet boundaries as well as the low-angle lath boundaries. The Nb-rich and V-rich MX carbonitrides with a mean size $40 \mathrm{~nm}$ and $20 \mathrm{~nm}$, respectively, were homogeneously distributed in ferritic matrix $[6,34$, $37,50,51]$.

\subsection{Creep tests at $923 \mathrm{~K}$ and $948 \mathrm{~K}$}

Fig. 1a demonstrates the creep rupture data of the $9 \% \mathrm{Cr}-3 \%$ Co steel at the temperatures of $923 \mathrm{~K}$ and $948 \mathrm{~K}$. Under the low applied stresses (lower than $140 \mathrm{MPa}$ ), the well-defined creep strength breakdowns [6, $34,50]$ were observed for both temperatures. As the creep temperature increased from 923 to $948 \mathrm{~K}$ the creep strength breakdown appearance shifted to shorter duration from $\sim 2000 \mathrm{~h}$ to $\sim 800 \mathrm{~h}$ (Fig. 1a). Moreover, the slopes of both curves at different temperatures were the same for ranges of the high and low applied stresses (Fig. 1a). Well-defined linear dependences between the applied stress and the minimum creep rate were revealed at two temperatures (Fig. 1b). The experimental data obeyed a power law relationship of the usual form $[1,6,52,53]$ :

$\dot{\varepsilon}_{\min }=A \times \sigma^{n^{*}} \exp \left(\frac{-Q}{R T}\right)$,

where $\dot{\varepsilon}_{\min }$ is the minimum creep rate, $\sigma$ is the applied stress, $Q$ is the activation energy for a plastic deformation, $R$ is the gas constant, $T$ is the absolute temperature, $A$ is a constant, and $n^{*}$ is the "apparent" stress exponent.

These plots provided the best linear fit with a regression coefficient of 0.99 for $n^{*}=12$ for $923 \mathrm{~K}$ and the whole applied stress interval. At $948 \mathrm{~K}$, two power-law relationships were characterized by the stress exponent of 5.5 and 15 in the applied stresses ranging of 80-120 and 120-180 MPa, respectively, with a regression coefficient of 0.99 for these two intervals. At this temperature, the creep strength breakdown (Fig. 1a) correlates with the power-law creep breakdown (Fig. 1b), while at $923 \mathrm{~K}$, no decrease in the apparent $n^{*}$ value attributed to creep strength breakdown occurred [6]. At $923 \mathrm{~K}$, the steady-state creep was controlled by the same process at a creep rate ranging from $10^{-6}$ to $10^{-10} \mathrm{~s}^{-1}$, while at $948 \mathrm{~K}$, the different mechanisms controlled creep behavior at the applied stresses less and higher than $120 \mathrm{MPa}$.

The creep rate $v s$. time and strain curves at $923 \mathrm{~K}$ and $948 \mathrm{~K}$ for some applied stresses (80, 100 and $120 \mathrm{MPa}$ ), at which the Z-phase formation has been observed (Fig. 2), are shown in Fig. 1c-f. The main creep characteristics are summarized in Table 1. An increase in the creep 

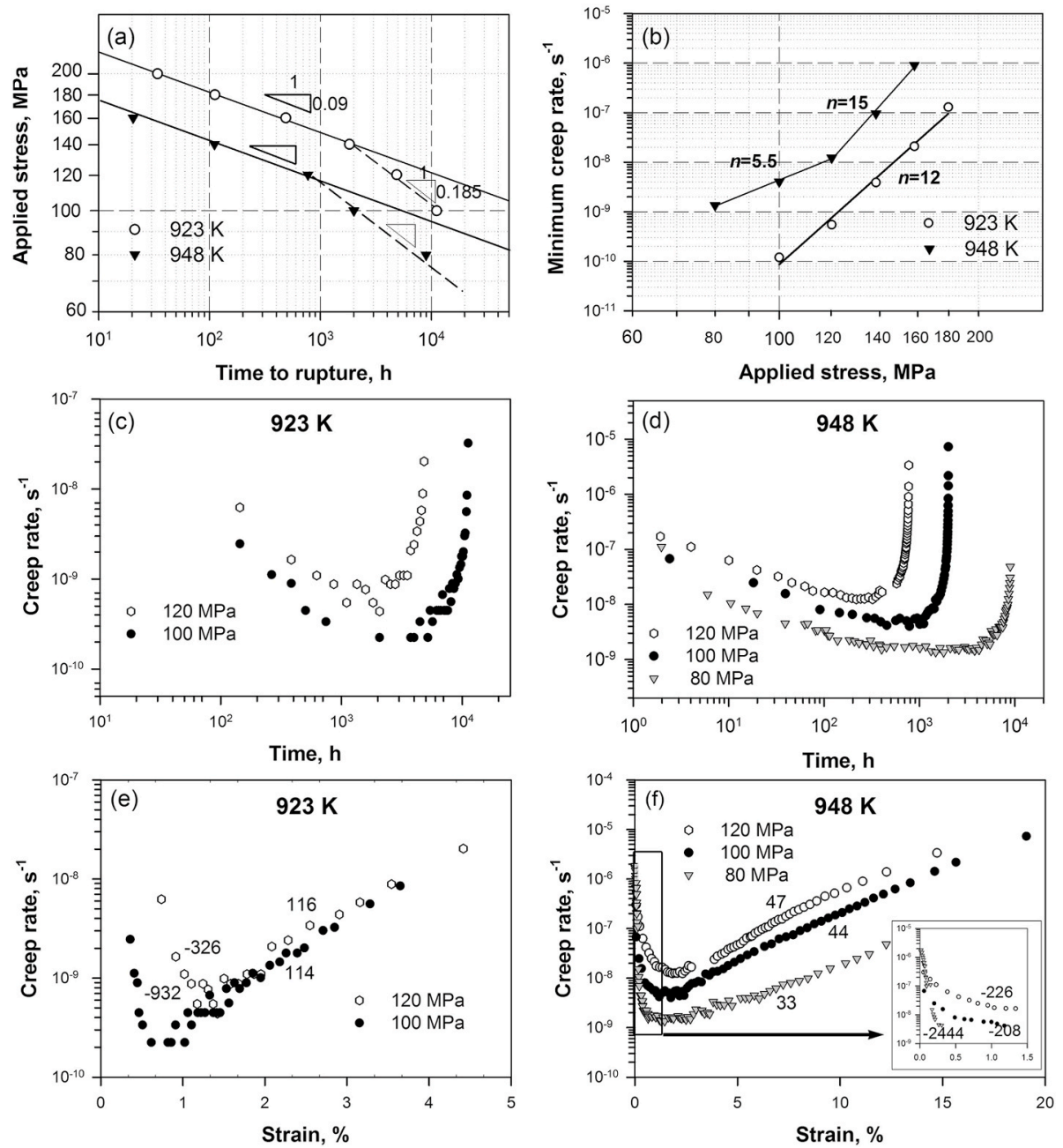

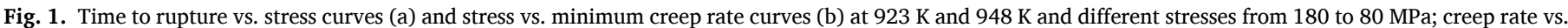

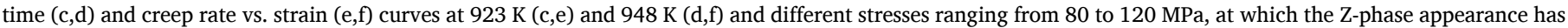
been revealed.

temperature:

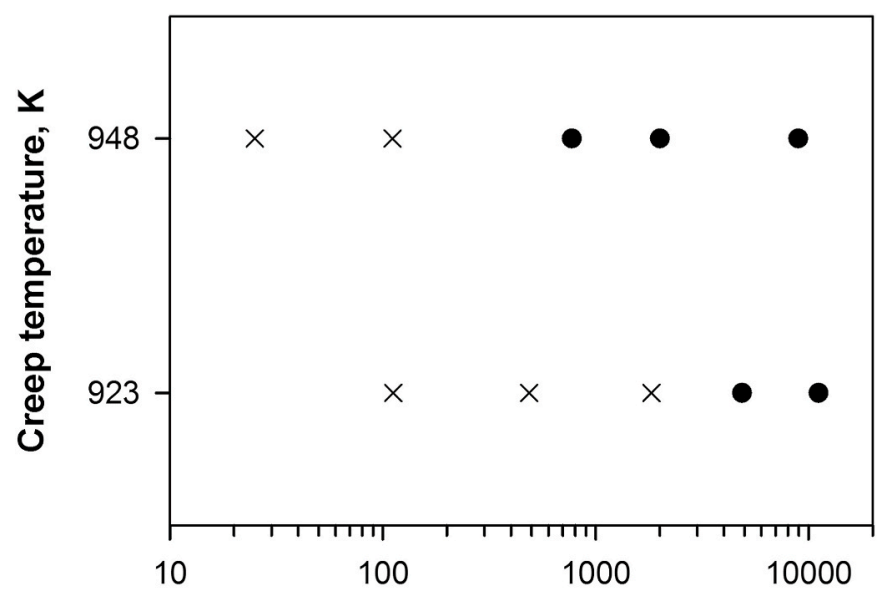

Time to rupture, $h$

Fig. 2. Time-temperature-transformation diagram for the Z-phase particles: black circles indicate the presence of the Z-phase particles and crosses indicate the absence of these particles.
(1) increased the total creep strain from $4-6 \%$ to $12-20 \%$ and strain to minimum creep rate from $0.7-1.4 \%$ to $1.2-1.8 \%$ (Fig. 1 e and f);

(2) increased the minimum creep rate from $10^{-10}$ to $10^{-8} \mathrm{~s}^{-1}$ for the applied stress of $120 \mathrm{MPa}$ and from $10^{-10}$ to $10^{-9} \mathrm{~s}^{-1}$ for the applied stress of $100 \mathrm{MPa}$ (Fig. 1c-f);

Table 1

Creep characteristics of 9\% $\mathrm{Cr}-3 \%$ Co steel at $923 \mathrm{~K}$ and $948 \mathrm{~K}$.

\begin{tabular}{|c|c|c|c|c|c|}
\hline \multirow[t]{3}{*}{ Creep conditions } & \multicolumn{2}{|l|}{$923 \mathrm{~K}$} & \multicolumn{3}{|l|}{$948 \mathrm{~K}$} \\
\hline & 120 & 100 & 120 & 100 & 80 \\
\hline & $\mathrm{MPa}$ & MPa & $\mathrm{MPa}$ & $\mathrm{MPa}$ & $\mathrm{MPa}$ \\
\hline Rupture time, $\mathrm{h}$ & 4869 & 11151 & 773 & 2084 & 8951 \\
\hline Total creep strain, $\%$ & 4.4 & 5.6 & 15 & 19 & 12 \\
\hline Minimum creep rate, $\mathrm{s}^{-1}$ & $\begin{array}{l}4.4 \times \\
10^{-10}\end{array}$ & $\begin{array}{l}1.2 \times \\
10^{-10}\end{array}$ & $\begin{array}{l}1.2 \times \\
10^{-8}\end{array}$ & $\begin{array}{l}4.4 \times \\
10^{-9}\end{array}$ & $\begin{array}{l}1.4 \times \\
10^{-9}\end{array}$ \\
\hline $\begin{array}{l}\text { Creep strain to minimal } \\
\text { creep rate, } \%\end{array}$ & 1.4 & 0.7 & 1.8 & 1.6 & 1.2 \\
\hline $\begin{array}{l}\text { Time to minimal creep rate, } \\
\%\end{array}$ & 2064 & 2724 & 322 & 892 & 1502 \\
\hline $\begin{array}{l}\text { The slope of the curve in } \\
\text { creep acceleration region } \\
(d \ln \dot{\varepsilon} / d \varepsilon)\end{array}$ & 116 & 114 & 47 & 44 & 33 \\
\hline Reduction in area, \% & 43 & 45 & 72 & 69 & 70 \\
\hline $\begin{array}{l}\text { The "apparent" stress } \\
\text { exponent, } n\end{array}$ & 12 & & 5.5 & & \\
\hline
\end{tabular}


(3) increased the reduction in area from $43-45 \%$ to $69-72 \%$ (Table 1).

Numbers in Fig. 1e and $\mathrm{f}$ indicate the slopes of the curves in the transient and tertiary creep regions $(d \ln \dot{\varepsilon} / d \varepsilon)$ estimated using the method suggested in Ref. [54], where $\dot{\varepsilon}$ and $\varepsilon$ are the creep rate and the creep strain, respectively. It is known [7,54-57] that this parameter, $d l n \dot{\varepsilon} / d \varepsilon$, well describes the kinetics reaction under transient and tertiary creep stages. The dependence of the creep rate on the strain in the acceleration region is described as [54]:

$\dot{\varepsilon}=\dot{\varepsilon}_{0} \exp (n \varepsilon) \exp (m \varepsilon) \exp (d \varepsilon) \exp (i \varepsilon)$

$d \ln \dot{\varepsilon} / d \varepsilon=n+m+d+i$

where $\dot{\varepsilon}_{0}$ is the initial creep rate, $n$ is the stress exponent from Eq. (1) and is 12 or 5.5 for the applied stresses ranging of $100-120 \mathrm{MPa}$ and $80-120$ $\mathrm{MPa}$ at $923 \mathrm{~K}$ and $948 \mathrm{~K}$, respectively, $m$ is the microstructure degradation parameter, $d$ is damage parameter due to the creep voids, and $i$ describes the localized creep deformation [54] and can be estimated using reduction in area (Table 1 ) that comprises $43-45 \%$ for $923 \mathrm{~K}$ and $69-72 \%$ for $948 \mathrm{~K}$. As suggested in Ref. [54], parameter $d$ is neglected because there is no evidence of cavitation at both temperatures. Transient creep behavior was nearly independent on temperature (Fig. 1e and f). Therefore, $d l n \dot{\varepsilon} / d \varepsilon$ resulted from the parameters $n, m$ and $i$ and comprised 114-116 for $923 \mathrm{~K}$ and 33-47 for $948 \mathrm{~K}$ for the whole applied stress interval, at which the Z-phase formation was observed (Fig. 2). At $923 \mathrm{~K}$ and applied stress ranging from 100 to $120 \mathrm{MPa}$, the $d \ln \dot{\varepsilon} / \varepsilon$ values were typical for long-term creep of the high chromium martensitic steels $[8,57]$ and indicative for a high rate of kinetic reactions. A decrease in the applied stress highly accelerates the kinetics reaction $[8,57]$. At $948 \mathrm{~K}$ and applied stress ranging from 80 to $120 \mathrm{MPa}$, the $d \ln \dot{\varepsilon} / \varepsilon$ values were typical for short-term creep of the high chromium martensitic steels; slowing down of kinetic reaction under tertiary creep was observed $[8,57]$.

\subsection{Evolution of the $M X$ carbonitrides during creep at $923 \mathrm{~K}$}

Fig. 2 demonstrates the creep conditions, at which the Z-phase formation has been revealed. Significant coarsening of the VX carbonitrides and their transformation into the Z-phase particles occurred under creep conditions at both temperatures. Fig. 3 shows the onset of MX $\rightarrow$ Z-phase transformation at $923 \mathrm{~K}$ after $4869 \mathrm{~h}$ under the applied stress of $120 \mathrm{MPa}$ (Fig. 3a-c) and the growth of VX carbonitrides up to $70 \mathrm{~nm}$ and development their transformation to Z-phase particles through the formation of "hybrid" particles after $11151 \mathrm{~h}$ under the applied stress of $100 \mathrm{MPa}$ (Fig. 3d-f). The irregular Z-phase particles (CrVN) with a tetragonal lattice with lattice parameters $a=0.286$ and $c=0.739 \mathrm{~nm}$ (Fig. 3a-c) exhibited an average chemical composition of metallic part of $50 \mathrm{wt} \%$ $(\mathrm{Cr}+\mathrm{Fe})$ and $50 \mathrm{wt} \%(\mathrm{~V}+\mathrm{Nb})(\mathrm{Fig} .4 \mathrm{a})$. These particles were found near VX carbonitrides or in contact with them in the form of "hybrid" particles, which consisted of V-rich and Cr-poor "core" with the cubic lattice and Cr-rich "rim" with the tetragonal lattice and corresponding chemical compositions (Fig. 3a and b, 4). No evidence of the formation of the Z-phase with the cubic lattice at $923 \mathrm{~K}$ was observed. The mean particle sizes of the VX carbonitrides and Z-phase were 62 and $59 \mathrm{~nm}$, respectively (Table 2 ).

Figs. 5 and 6 demonstrate particle size distributions of VX carbonitrides and Z-phase, respectively, at different temperatures. At $923 \mathrm{~K} /$ $120 \mathrm{MPa}$, the particle size distribution showed no evidence of the Zphase particle presence with sizes smaller than that of VX particles (Figs. 5a and 6a). The number ratio of the Z-phase particles and VX carbonitrides was 1: 6 (Table 2). An increase in the creep time up to 11 $151 \mathrm{~h}$ (the applied stress of $100 \mathrm{MPa}$ ) led to an increase in the fraction of the coarse particles with sizes ranging from 120 to $180 \mathrm{~nm}$ increased (Fig. 5b) that provided full dissolution of very fine particles with sizes smaller than $30 \mathrm{~nm}$. The mean size of the VX carbonitrides increased to $70 \mathrm{~nm}$ (Table 2). The complete dissolution of fine VX particles also increased the portion of the particles with sizes ranging from 50 to 100 $\mathrm{nm}$. These VX carbonitrides were susceptible to transformation into Zphase through the formation of "hybrid" particles. On the other hand, the coarse VX particles carbonitrides with sizes about $100 \mathrm{~nm}$ were the most resistant to transformation into the $\mathrm{Z}$ phase (Fig. $5 \mathrm{~b}$ ). The number ratio of the Z-phase particles and VX carbonitrides was 1 : 1 (Table 2). Moreover, after this creep rupture test, a $50 \%$ of initial number of the VX particles remained in the structure of the $9 \% \mathrm{Cr}-3 \%$ Co steel. The average size of the Z-phase particles significantly increased up to $200 \mathrm{~nm}$ (Table 2), wherein the fraction of the particles with sizes greater than $100 \mathrm{~nm}$ was $75 \%$ of the total amount of particles (Fig. 6b). Fast growth of Z-phase particles up to $200 \mathrm{~nm}$ leads to dissolution of nanoscale VX carbonitrides. The coarse Z-phase particles with a "hybrid" structure
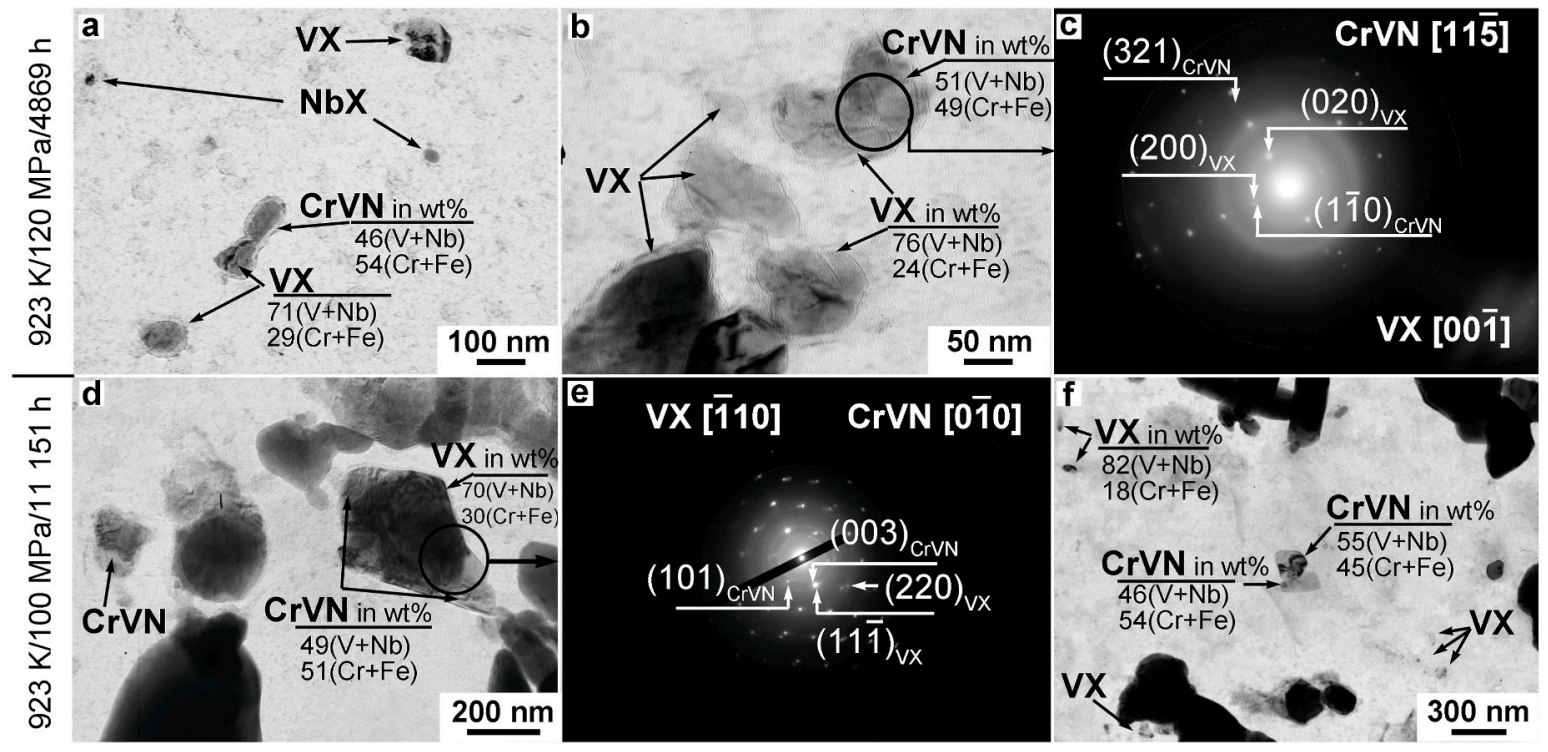

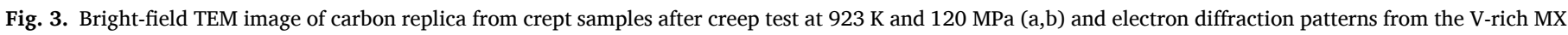

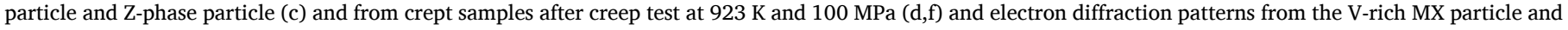
Z-phase particle (e). Circles in (b) and (d) indicate the places, where the electron diffractions were taken from. 

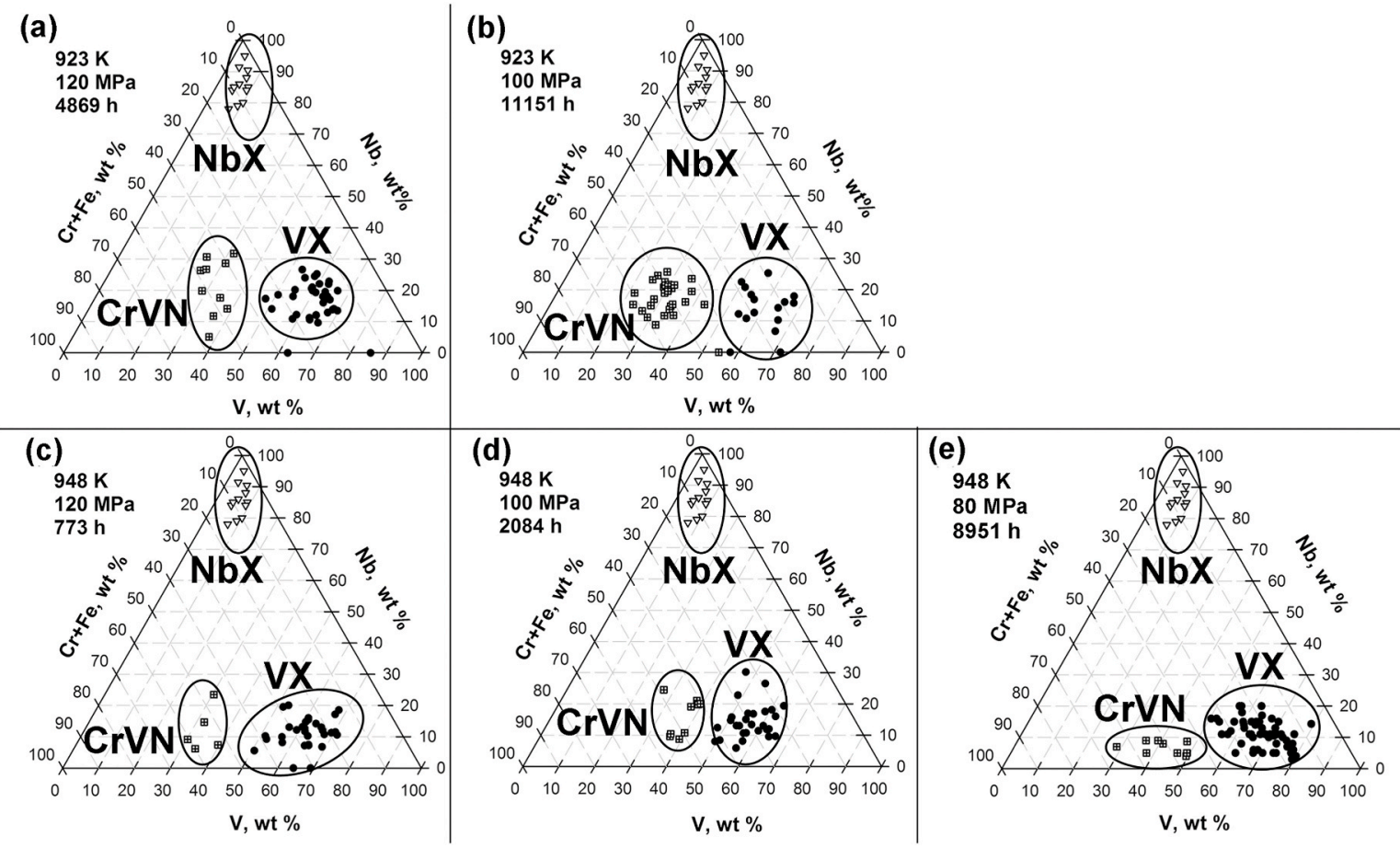

Fig. 4. The chemical compositions of the NbX, VX and Z-phase particles after different creep conditions: (a) $923 \mathrm{~K} / 120 \mathrm{MPa}$, (b) $923 \mathrm{~K} / 100 \mathrm{MPa}$, (c) $948 \mathrm{~K} / 120 \mathrm{MPa}$, (d) $948 \mathrm{~K} / 100 \mathrm{MPa}$, (e) $948 \mathrm{~K} / 80 \mathrm{MPa}$.

Table 2

The VX and Z-phase size and number ratio of VX: CrVN.

\begin{tabular}{|c|c|c|c|c|c|}
\hline \multirow{2}{*}{$\begin{array}{l}\text { Creep } \\
\text { condition }\end{array}$} & \multicolumn{2}{|l|}{$923 \mathrm{~K}$} & \multicolumn{3}{|l|}{$948 \mathrm{~K}$} \\
\hline & $\begin{array}{l}120 \mathrm{MPa} / \\
4869 \mathrm{~h}\end{array}$ & $\begin{array}{l}100 \mathrm{MPa} / \\
11151 \mathrm{~h}\end{array}$ & $\begin{array}{l}120 \\
\mathrm{MPa} / \\
773 \mathrm{~h}\end{array}$ & $\begin{array}{l}100 \mathrm{MPa} / \\
2084 \mathrm{~h}\end{array}$ & $\begin{array}{l}80 \mathrm{MPa} / \\
8951 \mathrm{~h}\end{array}$ \\
\hline $\begin{array}{l}\text { Mean size of } \\
\text { VX, nm }\end{array}$ & 62 & 70 & 46 & 59 & 85 \\
\hline $\begin{array}{c}\text { Mean size of } \\
\text { CrVN, nm }\end{array}$ & 59 & 200 & 28 & 41 & 142 \\
\hline VN: CrVN & $6: 1$ & $1: 1$ & $9: 1$ & $6: 1$ & $6: 1$ \\
\hline
\end{tabular}

coexisted with the VX carbonitrides. The average chemical composition of the Z-phase particles was $50 \mathrm{wt} \%(\mathrm{Cr}+\mathrm{Fe})$ and $50 \mathrm{wt} \%(\mathrm{~V}+\mathrm{Nb})$, whereas the fraction of vanadium and niobium in the VX carbonitrides decreased (Fig. 4b).

The chemical composition of the NbX carbonitrides insignificantly changed during creep at both temperatures (Fig. 4). No evidence of coarsening of these particles or their transformation into Z-phase during creep at $923 \mathrm{~K}$ and $948 \mathrm{~K}$ was revealed (Figs. 3 and 7).

\subsection{Evolution of the MX carbonitrides during creep at $948 \mathrm{~K}$}

Fig. 7 shows the formation of Z-phase at $948 \mathrm{~K}$. Under creep testing at $948 \mathrm{~K}$ and the applied stress of $120 \mathrm{MPa}$, the time to rupture of $774 \mathrm{~h}$, the sufficiently fine Z-phase particles with a cubic lattice were found on the $\mathrm{VX} /$ ferrite interfaces (Fig. $7 \mathrm{a}-\mathrm{c}$ ). An increase in the creep rupture time to $2084 \mathrm{~h}$ (the applied stress of $100 \mathrm{MPa}$ ) led to the appearance of two significant changes in the Z-phase (Fig. 7d-f). Firstly, the metastable Zphase particles with the cubic lattice nucleated on the VX/ferrite interface transformed into the thermodynamically stable Z-phase with the tetragonal crystal structure; the mean size of these particles was 41 nm (Fig. 7d-f and Table 2). Secondly, separate Z-phase particles with a tetragonal lattice formed through "hybrid" particles were also revealed (Fig. 7f). These separate Z-phase particles were coarser than those formed on the VX/ferrite interface; their average size was about $65 \mathrm{~nm}$
(Fig. 7f). Coarsening of the VX carbonitrides because of dissolution of the fine particles occurred together with their transformation into the Zphase particles. A further increase in the creep time up to $8951 \mathrm{~h}$ (creep rupture time under the applied stress of $80 \mathrm{MPa}$ ) led to a significant coarsening of the VX particles to $85 \mathrm{~nm}$ and the Z-phase to $142 \mathrm{~nm}$ (Fig. 7g-i and Table 2). The chemical compositions of the Z-phase particles having the cubic lattice and the tetragonal lattice were similar (Fig. 4).

The particle size distribution (Fig. 5c) showed that after creep test at $948 \mathrm{~K} / 120 \mathrm{MPa}$, the average size of the VX carbonitrides increased to 46 $\mathrm{nm}$, wherein both the fine particles with sizes below than $30 \mathrm{~nm}$ and the large particles with sizes greater than $100 \mathrm{~nm}$ were revealed. In contrast, the average size of the Z-phase particle was much smaller than VX carbonitrides and comprised $28 \mathrm{~nm}$ (Table 2), wherein the fraction of the particles with sizes below than $30 \mathrm{~nm}$ was about $60 \%$ (Fig. 6c). The number ratio of the Z-phase particles and VX carbonitrides was $1: 9$ (Table 2). After creep test at $948 \mathrm{~K} / 80 \mathrm{MPa}$, the fraction of the VX particles with sizes greater than $100 \mathrm{~nm}$ increased to $35 \%$ (Fig. 5e). The fraction of the Z-phase particles with sizes greater than $100 \mathrm{~nm}$ was $85 \%$ of the total amount of particles (Fig. 6e). The number ratio of the Zphase particles and VX carbonitrides was $1: 6 \mathrm{after} 8951 \mathrm{~h}$ of creep. The coarsening of VX carbonitrides becomes the main mechanism of microstructural degradation.

Thus, at $948 \mathrm{~K}$, hindering in situ $\mathrm{MX} \rightarrow Z$-phase transformation retains the significant portion of $\mathrm{VX}$ carbonitrides instead of their transformation into Z-phase even after high rupture times.

\section{Discussion}

\section{1. $M X \rightarrow Z$-phase transformation during creep at $923 \mathrm{~K}$ and $948 \mathrm{~K}$}

Two different nucleation mechanisms are realized in the $9 \% \mathrm{Cr}-3 \%$ Co martensitic steel during creep at temperatures of $923 \mathrm{~K}$ and $948 \mathrm{~K}$. The first nucleation mechanism is in-situ transformation of the cubic lattice of V-rich MX carbonitrides into Z-phase with tetragonal lattice starting from rim zone of VX particles and towards their core through the 

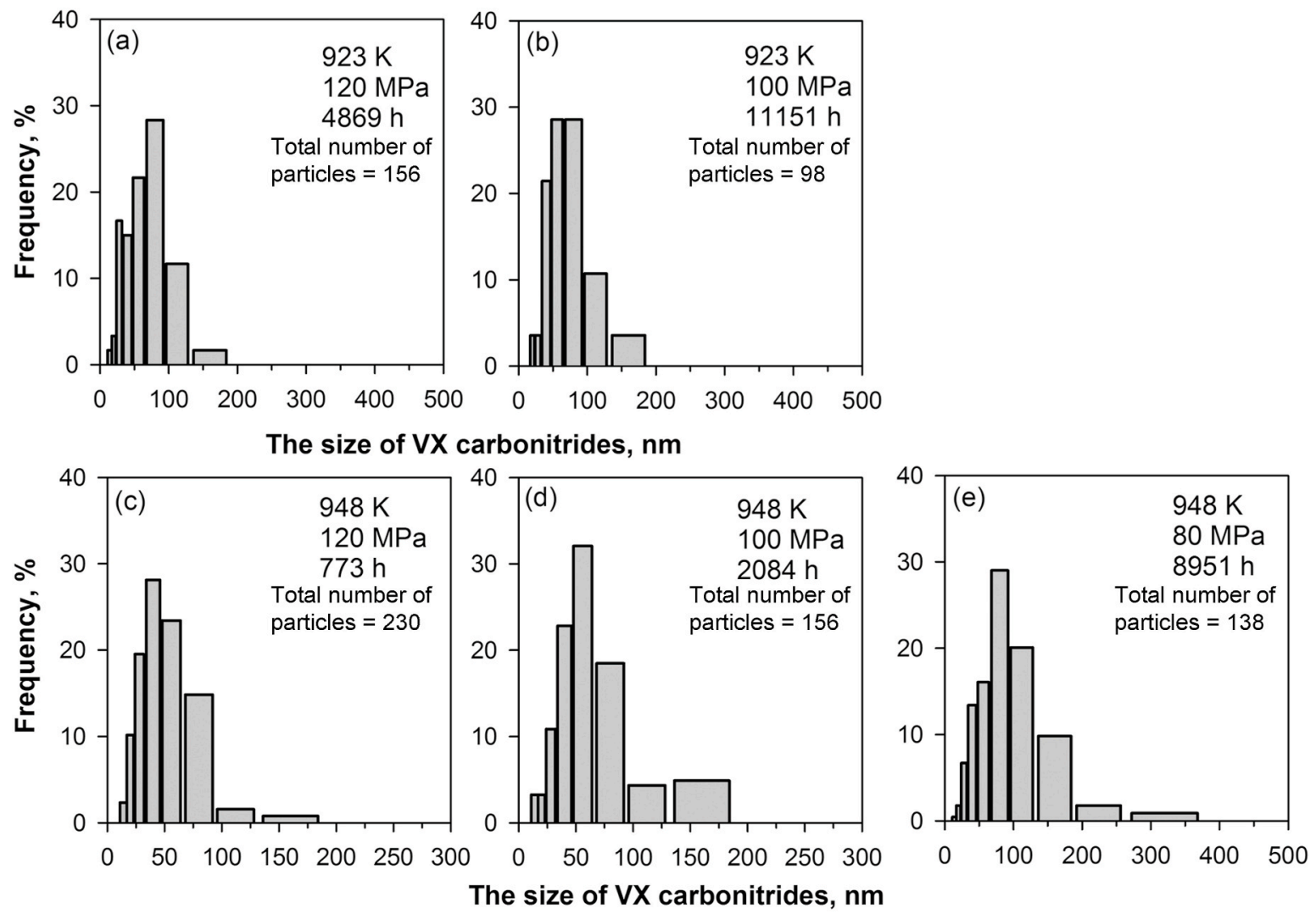

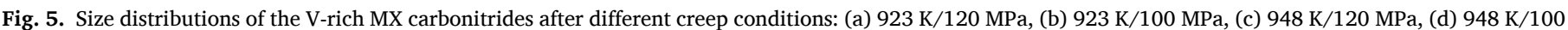
$\mathrm{MPa}$, (e) $948 \mathrm{~K} / 80 \mathrm{MPa}$.

formation of «hybrid » VX + Z-phase particles (Figs. 3 and 7d-e) [23-25, 29-31,33,35,38,39,41]. The sequence of the Z-phase formation according to the first mechanism can be written as (4):

VX carbonitride $\rightarrow$ «hybrid » VX + Z-phase particle $\rightarrow$ Z-phase with a tetragonal lattice

The interactions between dislocations and VX carbonitrides led to the creation of additional short-circuit diffusion paths for solutes, such as $\mathrm{Cr}$ and V. An incorporation of $\mathrm{Cr}$ atoms into cubic lattice of VX carbonitrides at rim zones provoked the formation of $\mathrm{Cr}$-rich rim of Z-phase along periphery of VX particles that posturized the distortion of cubic lattice with double layers of similar atoms alternating along the $c$ axis to give a ... CrCrVVCrCrVV ... sequence [23-30,35,38,41]. Such mechanism is observed under creep testing at $923 \mathrm{~K}$ and rupture time longer than $4500 \mathrm{~h}$ and at $948 \mathrm{~K}$ and rupture time longer than $2000 \mathrm{~h}$.

The presence of the Z-phase particles smaller than the VX carbonitrides, which is shown in Fig. $5 \mathrm{c}-\mathrm{e}$ and $6 \mathrm{c}-\mathrm{e}$, indicates the Z-phase nucleation occurred through another way. The Z-phase with the cubic lattice nucleates on the V-rich MX/ferrite interfaces with the following transformation into the Z-phase with the tetragonal lattice under creep testing at $948 \mathrm{~K}$ and rupture time of $773 \mathrm{~h}$. The sequence of the $\mathrm{Z}$-phase formation according to the second mechanism can be written as (5):

$\mathrm{VX} /$ ferrite interface $\rightarrow$ Z-phase with a cubic lattice $\rightarrow$ Z-phase with a tetragonal lattice

The Z-phase with the cubic lattice with a parameter of $\sim 0.404 \mathrm{~nm}$ was metastable phase which was transformed into the thermodynamically stable Z-phase with a tetragonal lattice with the parameters of $a=$ $0.286 \mathrm{~nm}$ and $c=0.739$ [14-16,19,21,26-29]. The Z-phase growth is accompanied with the dissolution of the fine VX particles (Fig. 5d) [8, $28]$.

The change in the nucleation mechanism of the Z-phase from direct in-situ transformation of the cubic lattice of the V-rich MX carbonitrides into the Z-phase with the tetragonal lattice to nucleation of the Z-phase on the $\mathrm{VX} /$ ferrite interface may be related to an increase in the $\mathrm{Cr}$ content [28-30,33] or creep/strain effect in the 9-12\% Cr steels [37]. However, the dependence of nucleation mechanism on the creep temperature is not mentioned yet [16-19,21-38,41]. As mentioned in Refs. $[22-31,33]$, the gradual rearrangement of the face-centered cubic lattice of the VX particles into the tetragonal lattice of the Z-phase provides the formation of the large Z-phase particles and full disappearance of the V-rich MX carbonitrides; the 9-12\% Cr steels lose their creep resistance after creep tests lasting more than $10000 \mathrm{~h} \mathrm{[16-19].} \mathrm{These} \mathrm{obtained}$ results are in accordance with literature data [22-31,33]. The first mechanism leads to the fast growth of Z-phase particles up to $200 \mathrm{~nm}$, which comprise $55 \%$ of all Z-phase particles at $923 \mathrm{~K}$ (Figs. 6b) and $25 \%$ of all Z-phase particles at $948 \mathrm{~K}$ (Fig. 6e).

High driving force for precipitation of the Z-phase allows reducing the critical size and the energy barrier for nucleation [58]. The driving forces for the bulk Z-phase are summarized in Table 3. These values are close to ones reported by H.K. Danielsen et al. [27]. Values of volume interdiffusion coefficient of $\mathrm{Cr}$ [59] and V [60] are also shown in Table 3. At $948 \mathrm{~K}$, the driving force for the formation of Z-phase is less by $\sim 19 \%$, while Cr diffusivity is higher by a factor of 35 in comparison with $923 \mathrm{~K}$ (Table 3). The lattice diffusion of $\mathrm{Cr}$ is the slowest process in situ transformation mechanism and, therefore, diffusion flux of $\mathrm{Cr}$ solutes controls the $\mathrm{MX} \rightarrow \mathrm{Z}$-phase reaction. As a result, the highest rate of this transformation is attained at $873 \mathrm{~K}$ for the $9 \% \mathrm{Cr}$ steels and $923 \mathrm{~K}$ for the $11-12 \% \mathrm{Cr}$ steels $[5,23,29,30,33,37]$. The diffusion of $\mathrm{Cr}$ solutes leads to increasing $\mathrm{Cr}$ content in MX carbonitrides (Fig. 4) and, therefore, this process increases Gibbs energy of these dispersoids. The replacement of first nucleation mechanism by second one strongly hinders the formation of Z-phase and refines their sizes. Dimensions of VX and Z-phase become nearly the same (Table 2). The occurrence of precipitation 

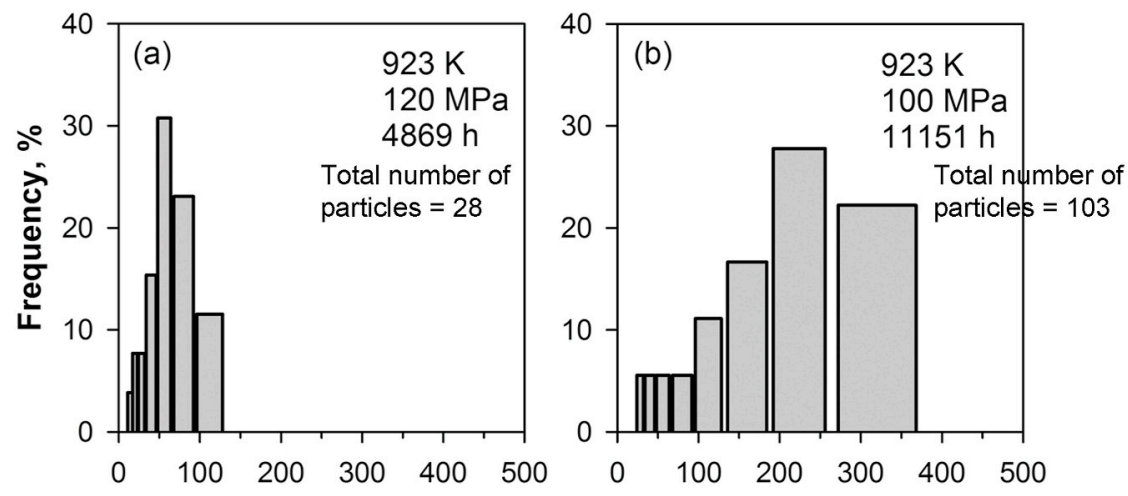

The size of CrVN nitrides, $\mathrm{nm}$
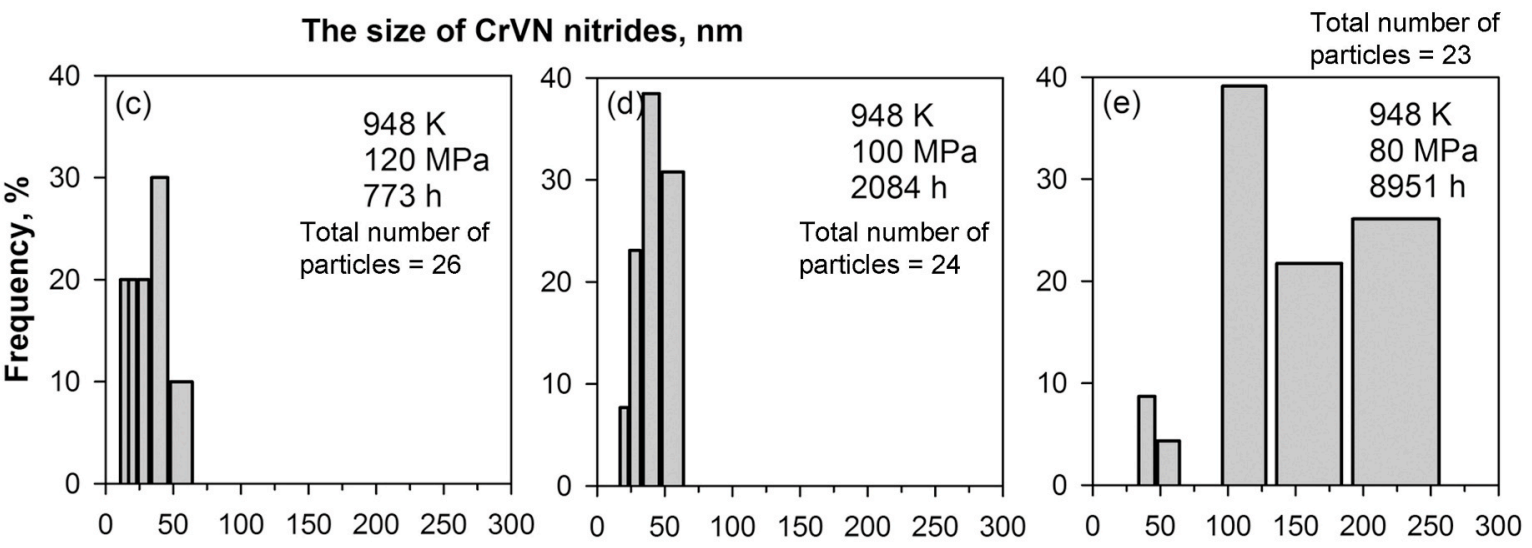

The size of CrVN nitrides, $\mathrm{nm}$

Fig. 6. Size distributions of the Z-phase particles after different creep conditions: (a) $923 \mathrm{~K} / 120 \mathrm{MPa}$, (b) $923 \mathrm{~K} / 100 \mathrm{MPa}$, (c) $948 \mathrm{~K} / 120 \mathrm{MPa}$, (d) $948 \mathrm{~K} / 100 \mathrm{MPa}$, (e) $948 \mathrm{~K} / 80 \mathrm{MPa}$.

sequence (5) could be attributed to low critical nucleus size for nucleation of cubic Z-phase due to coherency of the Z-phase/ferrite and Z-phase/MX interfaces. The Z-phase with the cubic lattice exhibits a parameter of $\sim 0.404 \mathrm{~nm}$ that is slightly lower than the VN lattice parameter [30]. This parameter provide a very low misfit of $2.3 \%$ between cubic lattice of this metastable precursor phase for tetragonal Z-phase and ferrite and, therefore, coherency of cubic Z-phase/ferrite interfaces. In addition, decreased driving force for Z-phase formation slows down the replacement of fine $\mathrm{V}(\mathrm{C}, \mathrm{N})$ by fine Z-phase particles since difference in Gibbs energy between two phases with nearly the same dimensions becomes insignificant. In the same time, cubic Z-phase $\rightarrow$ tetragonal Z-phase transformation promotes dissolution of the fine VX particles (Figs. 5 and 6).

\subsection{Effect of temperature on the Z-phase coarsening}

The coarsening behavior of spherical particles controlling by lattice diffusion in presumption that there are no elastic interactions (the Zphase and VX particle exhibit no coherent stress) is described by LifshitzSlyozov-Wagner (LSW) equations [61-66] (Eqs. (6)-(8)):

$d^{3}-d_{0}^{3}=K_{0}\left(t-t_{0}\right) \exp (-Q / R T)$

$K_{0}=\frac{8}{9} D_{V / C r}^{\alpha} \frac{\gamma V_{m}^{V X / Z \text { - phase }}}{R T} \frac{\left(1-X_{a}^{V X / Z-p h a s e}(\infty)\right)}{\left(X_{V X / Z}^{\alpha} \text {-phase }(\infty)-X_{\alpha}^{V X / Z-\text { phase }}\right)^{2}}$

$K_{\mathrm{p}}=K_{0} \exp (-Q / R T)$

where $K_{\mathrm{p}}$ is the coarsening rate constant; $d$ and $d_{0}$ are the current and initial particle sizes, respectively; $t$ and $t_{0}$ are the current and initial time, respectively; the growth exponent $n=3$ is attributed to lattice diffusion; $K_{0}$ is the preexponential constant; $Q$ is the apparent activation energy for particle growth; $R$ is the gas constant and $T$ is the absolute temperature. $D_{V / C r}^{\alpha}$ is diffusivity of $\mathrm{V}$ or $\mathrm{Cr}$ in ferrite, $\gamma$ is the interfacial energy, $V_{m}^{V X / Z-p h a s e}$ is the molar volume of the VX or Z-phase, $X_{\alpha}^{V X / Z \text {-phase }}(\infty)$ is the composition of the $\alpha$-ferrite in equilibrium with a spherical VX or Zphase of composition $X_{V X / Z \text {-phase }}^{\alpha}(\infty)$ across a flat interface $\mathrm{d}=\propto \mathrm{c}_{\mathrm{e}}$. Note that the initial state/time for the VX particles corresponds to tempering state $(3 \mathrm{~h})$ and $d_{0}$ comprises $20 \mathrm{~nm}$; the initial state/time for Z-phase corresponds to time, when the first Z-phase particles were observed (Fig. 2), and $d_{0}$ comprises $15 \mathrm{~nm}$ for $4869 \mathrm{~h}$ of creep test at $923 \mathrm{~K}$ (Figs. 6a) and $15 \mathrm{~nm}$ for $773 \mathrm{~h}$ of creep test at $948 \mathrm{~K}$ (Fig. 6c)).

Fig. 8 demonstrates the temperature dependence of the particle sizes. Ostwald ripening of both phases is described by Eq. (6) with high accuracy. The coarsening rate constants, $K_{\mathrm{p}}$, for the VX carbonitrides comprise $5.13 \times 10^{-30}$ and $1.85 \times 10^{-29} \mathrm{~m}^{3} \mathrm{~s}^{-1}$ for $923 \mathrm{~K}$ and $948 \mathrm{~K}$, respectively (Fig. 8a). So, an increase in the creep temperature accelerates the Ostwald ripening of VX carbonitrides by a factor of $\sim 28$ because of the dissolution of the fine VX particles (Fig. 5) that can attributed to accelerated diffusivity of $\mathrm{V}$ and $\mathrm{Cr}$ in the ferrite (Table 3). The coarsening rate constants, $K_{\mathrm{p}}$, for Z-phase particles comprise $3.45 \times$ $10^{-28}$ and $1.01 \times 10^{-28} \mathrm{~m}^{3} \mathrm{~s}^{-1}$ for $923 \mathrm{~K}$ and $948 \mathrm{~K}$, respectively (Fig. 8b). So, a decrease in the growth rate of the Z-phase at $948 \mathrm{~K}$ is in accordance with the fact that the Z-phase precipitation rate seems to be the highest at $873 \mathrm{~K}$ for the $9 \% \mathrm{Cr}$ steels $[25,29]$. As Eq. (8) is expressed in the form:

$\ln K_{\mathrm{p}}=\ln K_{0}-(Q / R)(1 / T)$

the apparent activation energy $Q$ for the particle growth can be estimated from the gradient of the Arrhenius plot of $\ln K_{\mathrm{p}} v s$. (1/T). The numerous studies carried on the kinetics of the Z-phase precipitation have revealed that their rate-controlling mechanism is the bulk diffusion of $\mathrm{Cr}$ atoms [23-31]. The apparent activation energy for this process is 

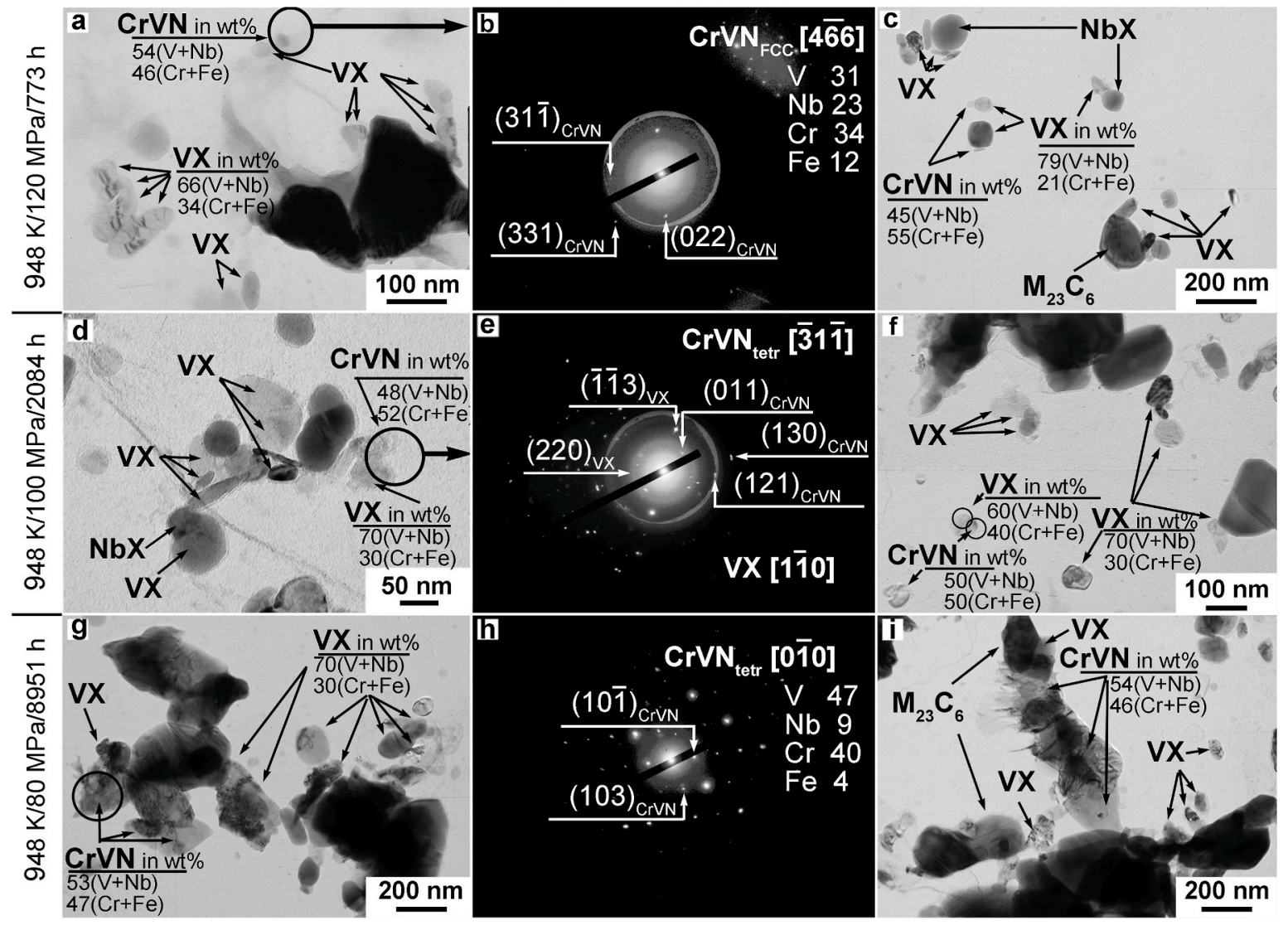

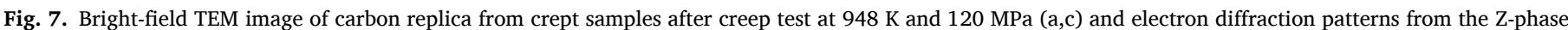

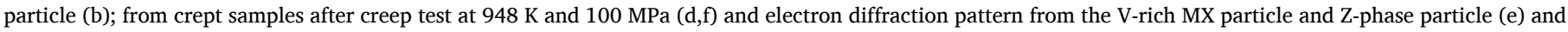

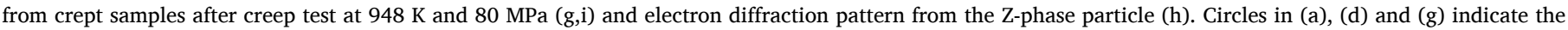
places, where the electron diffractions were taken from.

Table 3

Driving forces for the bulk Z-phase and volume interdiffusion coefficients of $\mathrm{Cr}$ [59] and V [60] calculated from equations for 0.1\% C-9\% Cr-1\% Mo steels.

\begin{tabular}{|c|c|c|c|}
\hline Temperature & $873 \mathrm{~K}$ & $923 \mathrm{~K}$ & $948 \mathrm{~K}$ \\
\hline Driving force, $\mathrm{J} / \mathrm{mol}$ & 3179 & 2448 & 2073 \\
\hline $\begin{array}{l}\text { Volume interduffusion coefficient of } \mathrm{Cr}, \mathrm{m}^{2} \\
\cdot \mathrm{s}^{-1}\end{array}$ & $7.8 \cdot 10^{-20}$ & $7.7 \cdot 10^{-19}$ & $2.2 \cdot 10^{-18}$ \\
\hline $\begin{array}{l}\text { Volume interduffusion coefficient of } \mathrm{V}, \mathrm{m}^{2} \\
\cdot \mathrm{s}^{-1}\end{array}$ & $2.0 \cdot 10^{-19}$ & $1.1 \cdot 10^{-18}$ & $6.0 \cdot 10^{-18}$ \\
\hline
\end{tabular}

about $355 \mathrm{~kJ} \mathrm{~mol}^{-1}$ that is close to the activation energy for volume diffusion of chromium in $\alpha$-Fe $\left(306 \pm 29 \mathrm{~kJ} \mathrm{~mol}^{-1}\right.$ for $9 \mathrm{CrMoV}$ steel at 870-1078 K [59]). Moreover, the apparent activation energy for growth of the VX carbonitrides comprises $378 \mathrm{~kJ} \mathrm{~mol}^{-1}$ that is also similar with the activation energy for volume diffusion of chromium in $\alpha$-Fe [59]. So, the growth rates of both VX carbonitrides and Z-phase are determined by the volume diffusion of $\mathrm{Cr}$ atoms.

\subsection{Effect of creep temperature on the interfacial energy of VX carbonitrides and Z-phase}

The growth particle rate strongly depended on the interfacial energy between particles and matrix. The interfacial energy values for the VX carbonitrides and Z-phase are rarely found in the literature $[21,32,46]$. The MX carbonitrides have a lattice parameter ranging from $0.414 \mathrm{~nm}$ to $0.447 \mathrm{~nm}$ depending on their chemical compositions and exhibit the Baker-Nutting (cube-on-edge) orientation relationship [1,26,29,32,37,
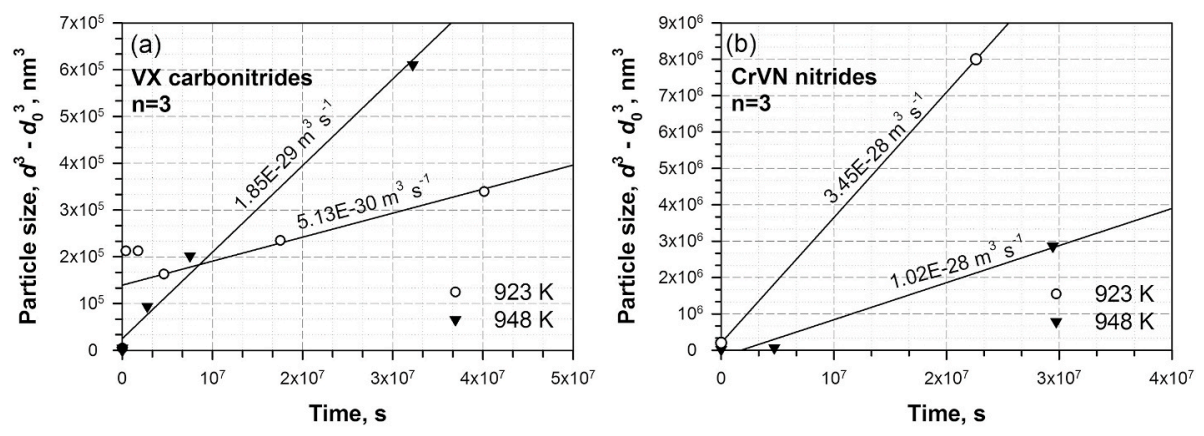

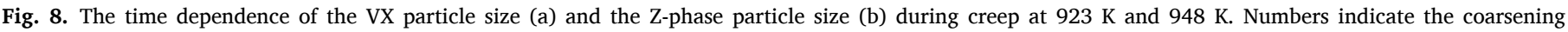
rate constant. 
67-69].

$\{100\}_{\mathrm{MX}}\left\|\{100\}_{\alpha-\mathrm{Fe}},<001>_{\mathrm{MX}}\right\|<011>_{\alpha-\mathrm{Fe}}$

The misfit $\delta$ between the Baker-Nutting oriented carbonitrides and ferrite in the (001) $)_{\alpha}$ plane can be defined as [65]:

$\delta=\frac{2\left(d_{M X}-\sqrt{2 d}_{\alpha}\right)}{\left(d_{M X}+\sqrt{2 d}_{\alpha}\right)}$

where $d_{M X}$ and $d_{\alpha}$ are the interplanar spacing of the particle and ferritic matrix, respectively. If a carbonitride exhibits a plate-like shape along $(001)_{\alpha}$ broad faces with square-like cross-section its misfit, $\delta$, is $\leq 3 \%$ that provides coherency of these interfaces with interfacial energy of $\sim 0.5 \mathrm{~J} \mathrm{~m}^{-2}$ [26,68-70]. VX carbonitrides having plate-like shape precipitate during tempering in this steel $[6,34,36,50,51]$. For the $9-12 \%$ Cr steels not containing Co, the value of the interfacial energy between the VX carbonitrides and matrix is reported to be $0.5 \mathrm{~J} \mathrm{~m}^{-2}[21,32,68$, 69]. An addition of Co to the $9 \% \mathrm{Cr}$ steels increases the interfacial energy between the VX carbonitrides and matrix up to $0.8-0.9 \mathrm{~J} \mathrm{~m}^{-2}$ [46]. The VX carbonitrides are enriched by $\mathrm{Cr}$, whereas ferrite matrix is enriched by Co. Metallic and covalent radii of $\mathrm{Cr}$ are slightly higher than $\mathrm{V}$ and, therefore, $d_{M X}$ parameter tends to increase with increasing $\mathrm{Cr}$ content. The same situation is observed in the Co-enriched ferrite matrix; $d_{\alpha}$ parameter also tends to increase. This leads to increase the misfit (Eq. (11)) [69]. As a result, $(001)_{\alpha}$ broad faces loss coherency and spheroidization takes place resulting in VX carbonitrides with round shape and average dimension of $50 \mathrm{~nm}$ [6,50,51]. MX carbonitrides exhibiting round shape have incoherent interfaces with interfacial energy ranging from 0.8 to $1.0 \mathrm{~J} \mathrm{~m}^{-2}$ in dependence on chemical composition [26,32, 46,67-69].

Coarsening behavior of these carbonitrides is well-described by interfacial energy of $0.8-0.85 \mathrm{~J} \mathrm{~m}^{-2}$ for both temperatures (Fig. 9). It seems that the increase in the interfacial energy up to $0.805-0.830 \mathrm{~J} \mathrm{~m}^{-2}$ facilitates the Z-phase formation that leads to the appearance of the first Z-phase particles already after $4869 \mathrm{~h}$ of creep at $923 \mathrm{~K}$ and $773 \mathrm{~h}$ at 948 K (Figs. 2, 3 and 7) instead of more than $10000 \mathrm{~h}$ for the Co-free P91 and P92 steels [16,19,21,25,29-31,47]. Moreover, creep at $948 \mathrm{~K}$ provides the increase in the interfacial energy of the VX carbonitrides from 0.805 to $0.830 \mathrm{~J} \mathrm{~m}^{-2}$ after $2000 \mathrm{~h}$ of test (Fig. 9b) that is accompanied by the predominance of the first mechanism of the Z-phase formation during creep at $948 \mathrm{~K}$ after $2000 \mathrm{~h}$.

The interfacial energy between the Z-phase and matrix is associated with the nucleation mechanism (Fig. 10). The values of the interfacial energy for the "hybrid" Z-phase particles are 0.555 and $0.582 \mathrm{~J} \mathrm{~m}^{-2}$ for $948 \mathrm{~K}$ and $923 \mathrm{~K}$, respectively (Fig. 10). Therefore, interfacial energy of "hybrid" particles is slightly higher than that of Z-phase nucleated as cubic phase with coherent interfaces on the $\mathrm{VX} /$ ferrite interfaces. Coarsening behavior is well described by low value of the interfacial energy of $0.4 \mathrm{~J} \mathrm{~m}^{-2}$ for cubic Z-phase at $948 \mathrm{~K}$ (Fig. 10b). This value of

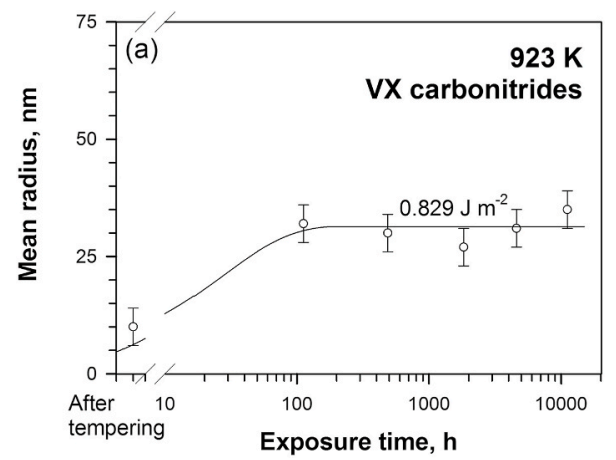

interfacial energy is typical for semi-coherent interfaces of nitrides [68, 69]. Lower interfacial energy of cubic Z-phase nucleated on VX/ferrite interfaces is responsible for their high resistance to coarsening in accordance with Gibbs-Thomson schema and dominance of second nucleation mechanism, since the low formation energy for the tetragonal Z-phase is not sufficient for nucleation of this phase with high energy incoherent interfaces [29,58]. This contradicts the work [37] in which it was reported that the combination of two mechanisms caused an avalanche-like growth of the Z-phase particles. On the other hand, non-typical behavior of the Z-phase precipitation has been observed during creep at $948 \mathrm{~K}$, at which the amount of Z-phase does not increase with increasing creep time, wherein the average particle size of this phase strongly increases.

\subsection{Z-phase formation and creep behavior}

The increase in creep temperature induced the significant Z-phase formation causing the nucleation of this phase for shorter times in the 9\% Cr-3\% Co steel (Fig. 2). As mentioned in Ref. [16-19,22,31,35,36], the Z-phase particle coarsening up to $1 \mu \mathrm{m}$ and full dissolution of MX carbonitrides were called as the major reasons for the creep strength breakdown appearance on the Stress $v$ s. Time to rupture dependence shown in Fig. 1a for the $11-12 \%$ Cr steels. The slopes of the curves shown in Fig. 1a for the region of short-term and long-term creep were the same for both temperatures of 923 and $948 \mathrm{~K}$. This indicates the similar reasons for the creep strength breakdown appearance at both temperatures. We reported previously $[6,34,50]$ that both nucleation and coarsening of the Z-phase cannot be the key changes caused such a strong deterioration in the creep strength properties at $923 \mathrm{~K}$, since the significant Z-phase coarsening was observed at times longer than time when the creep strength breakdown occurred [34]. The transformation of tempered martensite lath structure into the subgrain structure together with the coarsening of grain boundary particles may be crucial reasons for drop in the creep strength in the $9 \% \mathrm{Cr}$ steels $[6,44,45]$. The formation of Z-phase is accompanying process of microstructural evolution [37]. The appearance of the fine Z-phase particles with sizes compared with the VX carbonitrides, as shown in Fig. 3(a,c) and 7 (a-f), should not initiate the degradation of the creep strength because the precipitation strengthening due to the fine Z-phase and VX particles had to be the same [30,31,41,49].

K. Sawada et al. supposed $[16,18,19]$ that the increase in the Z-phase number increases the slope of curve of Stress $v s$. Time to rupture in the region of long-term creep. In the present work, the slopes of curves of Stress vs. Time to rupture (Fig. 1a) were independent of the Z-phase numbers: the slopes were the same for both 923 and $948 \mathrm{~K}$, but the Z-phase number is significantly higher after creep at $923 \mathrm{~K}$. At both creep temperatures, the significant amount of the VX carbonitrides retains in the structure that provides the same slope of the curves in the region of long-term creep. However, at 948K, the evolution of a

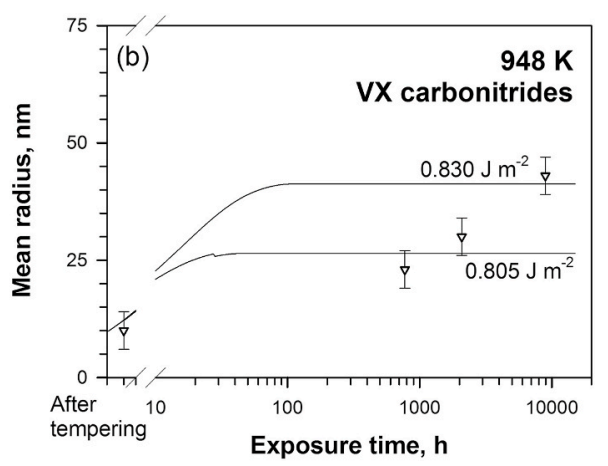

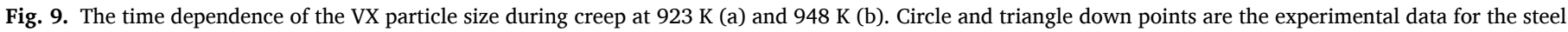

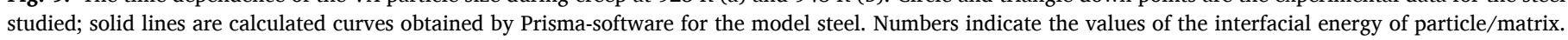



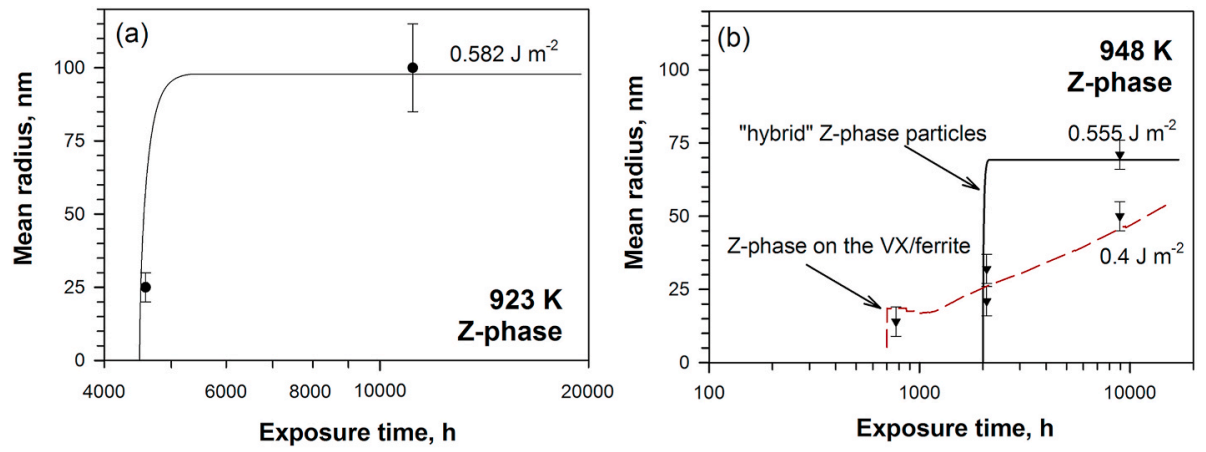

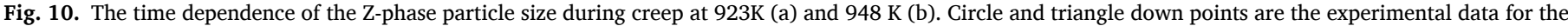

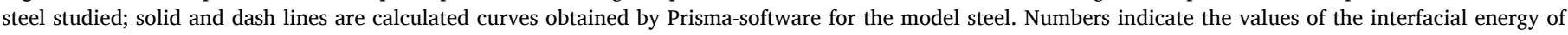
particle/matrix.

dispersion of MX carbonitrides is responsible for strong correlation between the creep strength breakdown and the power-law creep breakdown when the stress exponent, $n *$, drastically changes from 15 to 5.5. It means that threshold stress essentially exerted by a dispersion of MX carbonitrides disappears [12] because of extensive growth of VX carbonitrides. Precipitation sequence (5) plays a minor role in the power-law creep breakdown. The dominant processes under tertiary creep are the coarsening of Z-phase at $923 \mathrm{~K}$ and Cr-rich VX particles at 948K (Fig. 8). Thus, at $948 \mathrm{~K}$, the coarsening of Cr-rich VX particles is responsible for steady-state creep behavior typical for hot deformation [52,53].

The replacement of the VX carbonitrides by the Z-phase particles did not affect the slope of the curves in the creep acceleration region (dln $\dot{\varepsilon}$ / $d \varepsilon$ ), as the applied stress decreased from $120 \mathrm{MPa}$ to $100 \mathrm{MPa}$ for $923 \mathrm{~K}$ (Fig. 1e). Moreover, at $948 \mathrm{~K}$, the slope of the curves in the creep acceleration region $(d \ln \dot{\varepsilon} / d \varepsilon)$ decreased as the applied stress decreased from $120 \mathrm{MPa}$ to $80 \mathrm{MPa}$ (Fig. 1f). The slope of the curve in the creep acceleration region $(d \ln \dot{\varepsilon} / d \varepsilon)$ is determined by the microstructural parameter $m$, mainly, which shows the degradation of the structure in the creep acceleration region $(d \ln \dot{\varepsilon} / d \varepsilon)$ [54] taking in the account that $n$ and $i$ are similar for all applied stresses, at which the Z-phase particles have been observed (Table 1 ). This is a feature for both creep temperatures. So, the Z-phase coarsening up to $150-200 \mathrm{~nm}$ (Fig. 6) did not lead to acceleration of tertiary creep stage at both creep temperatures as long as at least $50 \%$ of initial number of the $\mathrm{VX}$ particles remained in the crept structure of the $9 \% \mathrm{Cr}-3 \%$ Co steel.

\section{Conclusions}

1) An increase in creep temperature significantly provokes the Z-phase formation causing the nucleation of this phase for shorter times in the $9 \% \mathrm{Cr}-3 \%$ Co steel and providing the change in the nucleation mechanism.

2) The Z-phase precipitation through in situ transformation $M X \rightarrow Z$ phase with formation of «hybrid $» \mathrm{VX}+\mathrm{Z}$-phase particles is observed under creep testing at $923 \mathrm{~K}$ with rupture time longer than $4500 \mathrm{~h}$ and at $948 \mathrm{~K}$ with rupture time longer than $2000 \mathrm{~h}$. Formation of Zphase is unimportant for the creep strength breakdown at both temperatures. However, at $923 \mathrm{~K}$, coarsening of Z-phase accompanied by progressive dissolution of $\mathrm{Cr}$-rich $\mathrm{VX}$ carbonitrides occurs with a high rate. Z-phase/VX ratio attains $1: 1$ in ruptured samples after about $11000 \mathrm{~h}$ of creep at $923 \mathrm{~K}$.

3) At $948 \mathrm{~K}$, the Z-phase nucleates on the MX/ferrite surface after $773 \mathrm{~h}$ of creep. This process is accompanied by Ostwald ripening of $\mathrm{Cr}$-rich VX carbonitrides. The coarse VX particles are resistant to the MX $\rightarrow$ cubic Z-phase $\rightarrow$ tetragonal Z-phase transformation. Z-phase/VX ratio attains $1: 6$ in ruptured samples after about $9000 \mathrm{~h}$ of creep. The power-low breakdown appearance, when the stress exponent, $n *$, changes from 15 to 5.5 , is contributed to the coarsening of Cr-rich VX carbonitrides.

4) The nucleation mechanism determines the interfacial energy between the Z-phase and matrix. A lower value of the interfacial energy was obtained for Z-phase nucleated on the VX/ferrite surface that leads to slower growth rate of these particles during creep at $948 \mathrm{~K}$ compared with $923 \mathrm{~K}$. The coarsening rate constants, $K_{\mathrm{p}}$, for Z-phase particles comprise $3.45 \times 10^{-28}$ and $1.01 \times 10^{-28} \mathrm{~m}^{3} \mathrm{~s}^{-1}$ for $923 \mathrm{~K}$ and $948 \mathrm{~K}$, respectively. The apparent activation energy for the Zphase precipitation is about $355 \mathrm{~kJ} \mathrm{~mol}^{-1}$ that is close to the activation energy for volume diffusion of chromium in $\alpha$-Fe.

5) The precipitation and coarsening of Z-phase particles up to 150-200 $\mathrm{nm}$ does not lead to the creep strength breakdown appearance and the acceleration of tertiary creep stage at both creep temperatures as long as at least $50 \%$ of initial number of the $\mathrm{VX}$ particles remains in the structure of the $9 \% \mathrm{Cr}-3 \%$ Co steel.

\section{Data availability}

The raw/processed data required to reproduce these findings cannot be shared at this time as the data also forms part of an ongoing study.

\section{CRediT authorship contribution statement}

A. Fedoseeva: Conceptualization, Methodology, Software, Investigation, Visualization, Writing - original draft, Writing - review \& editing, Funding acquisition. I. Nikitin: Investigation, Formal analysis, Visualization. N. Dudova: Investigation, Formal analysis, Writing - original draft. R. Kaibyshev: Supervision, Methodology, Writing - original draft.

\section{Declaration of competing interest}

The authors declare that they have no known competing financial interests or personal relationships that could have appeared to influence the work reported in this paper.

\section{Acknowledgments}

This study was financially supported by Russian Science Foundation under grant No. 19-73-10089. TEM analysis was performed by using an equipment at the Joint Research Center, «Technology and Materials», Belgorod National Research University.

\section{References}

[1] F. Abe, T.-U. Kern, R. Viswanathan, Creep-resistant Steels, Woodhead Publishing, Cambridge, 2008

[2] R. Viswanathan, W. Bakker, Materials for ultrasupercritical coal power plants boiler materials: Part I, J. Mater. Eng. Perform. 10 (2001) 81-95, https://doi.org/ 10.1361/105994901770345394. 
[3] R.O. Kaybyshev, V.N. Skorobogatykh, I.A. Shchenkova, New martensitic steels for fossil power plant: creep resistance, Phys. Met. Metallogr. 109 (2010) 186-200, https://doi.org/10.1134/S0031918X10020110.

[4] H.K.D.H. Bhadeshia, Design of ferritic creep-resistant steels, ISIJ Int. 41 (2001) 626-640, https://doi.org/10.2355/isijinternational.41.626.

[5] J. Hald, High-alloyed martensitic steel grades for boilers in ultra-supercritical power plants Materials for Ultra-Supercritical and Advanced Ultra-Supercritical Power Plants, in: A. Di Gianfrancesco (Ed.), Materials for Ultra-supercritical and Advanced Ultra-supercritical Power Plant, Woodhead Publishing, Cambridge, 2017, pp. 77-97, https://doi.org/10.1016/B978-0-08-100552-1.00003-8.

[6] A. Fedoseeva, N. Dudova, R. Kaibyshev, Creep strength breakdown and microstructure evolution in a 3\%Co modified P92 steel, Mater. Sci. Eng., A 654 (2016) 1-12, https://doi.org/10.1016/j.msea.2015.12.027.

[7] R. Mishnev, N. Dudova, A. Fedoseeva, R. Kaibyshev, Microstructural aspects of superior creep resistance of a $10 \% \mathrm{Cr}$ martensitic steel, Mater. Sci. Eng., A 678 (2016) 178-189, https://doi.org/10.1016/j.msea.2016.09.096.

[8] R. Mishnev, N. Dudova, R. Kaibyshev, On the origin of the superior long-term creep resistance of a 10\% Cr steel, Mater. Sci. Eng., A 713 (2018) 161-173, https://doi. org/10.1016/j.msea.2017.12.066.

[9] P. Prakash, J. Vanaja, G.V. Prasad Reddy, K. Laha, G.V.S. Nageswara Rao, On the effect of thermo-mechanical treatment on creep deformation and rupture behaviour of a reduced activation ferritic-martensitic steel, J. Nucl. Mater. 520 (2019) 65-77, https://doi.org/10.1016/j.jnucmat.2019.04.014.

[10] F. Abe, Progress in creep-resistant steels for high efficiency coal-fired power plants, J. Pressure Vessel Technol. 138 (2016), https://doi.org/10.1115/1.4032372, 040804.

[11] A. Fedoseeva, N. Dudova, R. Kaibyshev, Effect of stresses on the structural changes in high-chromium steel upon creep, Phys. Met. Metallogr. 118 (2017) 591-600, https://doi.org/10.1134/S0031918X17040032.

[12] N. Dudova, R. Mishnev, R. Kaibyshev, Creep behavior of a $10 \% \mathrm{Cr}$ heat-resistant martensitic steel with low nitrogen and high boron contents at $650{ }^{\circ} \mathrm{C}$, Mater. Sci. Eng., A 766 (2019) 138353, https://doi.org/10.1016/j.msea.2019.138353.

[13] K. Kimura, Review of allowable stress and new guideline of long-term creep strength assessment for high $\mathrm{Cr}$ ferritic creep resistant steels, Mater. A. T. High. Temp. 25 (2008) 121-129, https://doi.org/10.3184/096034008X354864.

[14] A. Fedoseeva, N. Dudova, R. Kaibyshev, A. Belyakov, Effect of tungsten on creep behavior of $9 \% \mathrm{Cr}-3 \%$ Co martensitic steels, Metals 7 (2017) 573, https://doi.org/ 10.3390/met7120573.

[15] M. Taneike, F. Abe, K. Sawada, Creep-strengthening of steel at high temperatures using nano-sized carbonitride dispersions, Nature 424 (2003) 294-296, https:// doi.org/10.1038/nature01740.

[16] K. Sawada, H. Kushima, K. Kimura, Z-phase formation during creep and aging in 9 $12 \%$ Cr heat resistant steels, ISIJ Int. 46 (2006) 769-775, https://doi.org/10.2355 isijinternational.46.769.

[17] F. Abe, V. Taneike, K. Sawada, Alloy design of creep resistant $9 \mathrm{Cr}$ steel using a dispersion of nano-sized carbonitrides, Int. J. Pres. Ves. Pip. 84 (2007) 3-12, https://doi.org/10.1016/j.ijpvp.2006.09.003.

[18] K. Sawada, H. Kushima, K. Kimura, M. Tabuchi, Z-phase formation and its effect on long-term creep strength in $9-12 \% \mathrm{Cr}$ creep resistant steels, Trans. Indian Inst. Met. 63 (2010) 117-122, https://doi.org/10.1007/s12666-010-0016-y.

[19] K. Sawada, H. Kushima, M. Tabuchi, K. Kimura, Effect of creep deformation on Z phase formation in Gr.91 steel, Mater. Sci. Technol. 30 (2014) 12-16, https://doi. org/10.1179/1743284713Y.0000000309.

[20] A. Goecmen, R. Steins, Ch Solenthaler, P.J. Uggowitzer, M.O. Speidel, Precipitation behaviour and stability of nitrides an high nitrogen martensitic $9 \%$ and $12 \%$ chromium steels, ISIJ Int. 36 (1996) 768-776, https://doi.org/10.2355/ isijinternational.36.768.

[21] J. Hald, L. Korcakova, Precipitate stability in creep resistant ferritic steels experimental investigations and modelling, ISIJ Int. 43 (2003) 420-427, https:// doi.org/10.2355/isijinternational.43.420.

[22] J. Hald, Microstructure and long-term creep properties of $9-12 \% \mathrm{Cr}$ steels, Int. J. Pres. Ves. Pip. 85 (2008) 30-37, https://doi.org/10.1016/j.ijpvp.2007.06.010.

[23] L. Cipolla, H.K. Danielsen, D. Venditti, P.E. Di Nunzio, J. Hald, M.A.J. Somers, Conversion of MX nitrides to Z-phase in a martensitic $12 \% \mathrm{Cr}$ steel, Acta Mater. 58 (2010) 669-679, https://doi.org/10.1016/j.actamat.2009.09.045.

[24] H.K. Danielsen, J. Hald, Behaviour of Z-phase in 9-12\%Cr steels, Energy Mater. Mater. Sci. Eng. Energy Syst. 1 (2006) 49-57, https://doi.org/10.1179/ 174892306 X99732.

[25] H.K. Danielsen, Precipitation process of Z-phase in 9-12\%Cr steels, in: Proc. 7th Int. Conf. On "Advances in Materials Technology for Fossil Power Plants", ASM Int., Waikoloa, HI, USA, October 2013, pp. 1104-1115.

[26] L. Cipolla, H.K. Danielsen, P.E. Di Nunzio, D. Venditti, J. Hald, M.A.J. Somers, On the role of $\mathrm{Nb}$ in Z-phase formation in a $12 \% \mathrm{Cr}$ steel, Scripta Mater. 63 (2010) 324-327, https://doi.org/10.1016/j.scriptamat.2010.04.025.

[27] H.K. Danielsen, J. Hald, A thermodynamic model of the Z-phase $\mathrm{Cr}(\mathrm{V}, \mathrm{Nb}) \mathrm{N}$, Calphad 21 (2007) 505-514, https://doi.org/10.1016/j.calphad.2007.04.001.

[28] H.K. Danielsen, J. Hald, On the nucleation and dissolution process of Z-phase $\mathrm{Cr}(\mathrm{V}$, $\mathrm{Nb}) \mathrm{N}$ in martensitic 12\%Cr steels, Mater. Sci. Eng., A 505 (2009) 169-177, https:// doi.org/10.1016/j.msea.2008.11.019.

[29] H.K. Danielsen, P.E. Di Nunzio, J. Hald, Kinetics of Z-phase precipitation in 9 to 12 pct Cr steels, Metall. Mater. Trans. 44 (2013) 2445-2452, https://doi.org/ 10.1007/s11661-012-1583-9.

[30] H.K. Danielsen, Review of Z phase precipitation in 9-12 wt \%Cr steels, Mater. Sci. Technol. 32 (2016) 126-137, https://doi.org/10.1179/ $1743284715 Y .0000000066$.
[31] F. Liu, M. Rashidi, L. Johansson, J. Hald, H.-O. Andren, A new 12\% chromium steel strengthened by Z-phase precipitates, Scripta Mater. 113 (2016) 93-96, https:// doi.org/10.1016/j.scriptamat.2015.10.030.

[32] C. Kocer, T. Abe, A. Soon, The Z-phase in $9-12 \% \mathrm{Cr}$ ferritic steels: a phase stability analysis, Mater. Sci. Eng., A 505 (2009) 1-5, https://doi.org/10.1016/j. msea.2008.10.028.

[33] R. Kaibyshev, V. Skorobogatykh, I. Shchenkova, Formation of the Z-phase and prospects of martensitic steels with $11 \% \mathrm{Cr}$ for operation above $590{ }^{\circ} \mathrm{C}$, Met. Sci. Heat Treat. 52 (2010) 90-99, https://doi.org/10.1007/s11041-010-9239-0.

[34] A. Fedoseeva, N. Dudova, R. Kaibyshev, Effect of tungsten on a dispersion of M(C, N) carbonitrides in $9 \% \mathrm{Cr}$ steels under creep conditions, Trans. Indian Inst. Met. 69 (2016) 211-215, https://doi.org/10.1007/s12666-015-0767-6.

[35] A. Strang, V. Vodarek, Z-phase formation in martensitic $12 \mathrm{CrMoVNb}$ steel, Mater. Sci. Technol. 12 (1996) 552-556, https://doi.org/10.1179/mst.1996.12.7.552.

[36] V. Sklenicka, K. Kucharova, M. Svoboda, L. Kloc, J. Bursik, A. Kroupa, Long-term creep behavior of 9-12\%Cr power plant steels, Mater. Char. 51 (2003) 35-48, https://doi.org/10.1016/j.matchar.2003.09.012.

[37] A. Fedoseeva, I. Nikitin, N. Dudova, R. Kaibyshev, Strain-induced Z-phase formation in a 9\% Cr-3\% Co martensitic steel during creep at elevated temperature, Mater. Sci. Eng., A 724 (2018) 29-36, https://doi.org/10.1016/j. msea.2018.03.081.

[38] I. Letofsky-Papst, P. Warbichler, F. Hofer, E. Letofsky, H. Cerjak, On the occurrence of Z-phase in a creep-tested $10 \% \mathrm{Cr}$ steel, Z. Metallkd 95 (2004) 18-21, https://doi, org/10.3139/146.017905.

[39] D.H. Jack, K.H. Jack, Structure of Z-phase, NbCrN, J. Iron Steel Inst. 210 (1972) 790-792.

[40] F.-Sh Yin, W.-S. Jung, Nanosized MX precipitates in ultra-low carbon ferritic/ martensitic heat-resistant steels, Metall. Mater. Trans. 40A (2009) 302-309, https://doi.org/10.1007/s11661-008-9716-x.

[41] J. Hald, Prospects for martensitic $12 \% \mathrm{Cr}$ steels for advanced steam power plants, Trans. Indian Inst. Met. 69 (2016) 183-188, https://doi.org/10.1007/s12666-0150793-4.

[42] M. Yoshizawa, M. Igarashi, K. Moriguchi, A. Iseda, H. Ghassemi-Armaki, K. Maruyama, Effect of precipitates on long-term creep deformation properties of P92 and P122 type advanced ferritic steels for USC power plants, Mater. Sci. Eng., A 510-511 (2009) 162-168, https://doi.org/10.1016/j.msea.2008.05.055.

[43] J. Svoboda, H. Riedel, Modeling of spontaneous transformation of nitrides to Z phase accounting for stress relaxation by diffusion and interface activity, Comput. Mater. Sci. 161 (2019) 24-34, https://doi.org/10.1016/j.commatsci.2019.01.030.

[44] H.Gh Armaki, R.P. Chen, K. Maruyama, M. Igarashi, Premature creep failure in strength enhanced high $\mathrm{Cr}$ ferritic steels caused by static recovery of tempered martensite lath structures, Mater. Sci. Eng., A 527 (2010) 6581-6588, https://doi. org/10.1016/j.msea.2010.07.037.

[45] H.Gh Armaki, R.P. Chen, S. Kano, K. Maruyama, Y. Hasegawa, M. Igarashi, Straininduced coarsening of nanoscale precipitates in strength enhanced high Cr ferritic steels, Mater. Sci. Eng., A 532 (2012) 373-380, https://doi.org/10.1016/j msea.2011.10.105.

[46] A. Fedoseeva, E. Tkachev, V. Dudko, N. Dudova, R. Kaibyshev, Effect of alloying on interfacial energy of precipitation/matrix in high-chromium martensitic steels, J. Mater. Sci. 52 (2017) 4197-4209, https://doi.org/10.1007/s10853-016-0654-5.

[47] A.E. Fedoseeva, P.A. Kozlov, V.A. Dudko, V.N. Skorobogatykh, I.A. Shchenkova, R. O. Kaibyshev, Microstructural changes in steel 10Kh9V2MFBR during creep for 40000 hours at $600^{\circ} \mathrm{C}$, Phys. Met. Metallogr. 116 (2015) 1047-1056, https://doi. org /10.7868/S0015323015080045.

[48] V.A. Dudko, A.E. Fedoseeva, A.N. Belyakov, R.O. Kaibyshev, Influence of the carbon content on the phase composition and mechanical properties of P92-type steel, Phys. Met. Metallogr. 116 (2015) 1165-1174, https://doi.org/10.7868/ S0015323015110054.

[49] I. Nikitin, A. Fedoseeva, R. Kaibyshev, Strengthening mechanisms of creepresistant $12 \% \mathrm{Cr}-3 \%$ Co steel with low N and high B contents, J. Mater. Sci. 55 (2020) 7530-7545, https://doi.org/10.1007/s10853-020-04508-7.

[50] A.E. Fedoseeva, I.S. Nikitin, N.R. Dudova, R.O. Kaibyshev, Formation of Z-phase particles in a martensitic $9 \% \mathrm{Cr}$ steel during creep at $650^{\circ} \mathrm{C}$ and their influence on the creep, Russ. Metall. 2019 (2019) 932-938, https://doi.org/10.1134/ S0036029519100069.

[51] A.E. Fedoseeva, I.S. Nikitin, N.R. Dudova, R.O. Kaibyshev, The effect of creep and long annealing conditions on the formation of the Z-phase particles, Phys. Met. Metallogr. 121 (2020) 561-567, https://doi.org/10.1134/S0031918X20060058.

[52] J. Cadek, Creep in Metallic Materials, Academia, Prague, 1994.

[53] M.E. Kassner, M.T. Pérez-Prado, Fundamentals of Creep in Metals and Alloys, first ed., Elsevier, New York, 2004.

[54] F. Abe, Creep behavior, deformation mechanisms and creep life of mod.9Cr-1Mo steel, Metall. Mater. Trans. 46 (2015) 5610-5625, https://doi.org/10.1007/ s11661-015-3144-5.

[55] J. Vanaja, K. Laha, M.D. Mathew, Effect of tungsten on primary creep deformation and minimum creep rate of reduced activation ferritic-martensitic steel, Metall. Mater. Trans. 45 (2014) 5076-5084, https://doi.org/10.1007/s11661-014-2472-1.

[56] J. Vanaja, K. Laha, Assessment of tungsten content on tertiary creep deformation behavior of reduced activation ferritic-martensitic steel, Metall. Mater. Trans. 46 (2016) 4669-4679, https://doi.org/10.1007/s11661-015-3075-1.

[57] E. Tkachev, A. Belyakov, R. Kaibyshev, Creep strength breakdown and microstructure in a $9 \% \mathrm{Cr}$ steel with high B and low $\mathrm{N}$ contents, Mater. Sci. Eng., A 772 (2020) 138821, https://doi.org/10.1016/j.msea.2019.138821.

[58] D.A. Porter, K.E. Esterling, M. Sherif, Phase Transformation in Metals and Alloys, third ed., CRS Press, 2009. 
[59] Z. Tokei, K. Hennesen, H. Viefhaus, H.J. Grabke, Diffusion of chromium in ferritic and austenitic 9-20 wt-\%chromium steels, Mater. Sci. Technol. 16 (2000) 1129-1138, https://doi.org/10.1179/026708300101507055.

[60] J. Čermák, J. Ružičková, A. Pokorná, Tracer diffusion of vanadium in FeCr ferritic alloys, Scripta Metall. Mater. 33 (1995) 1069-1073, https://doi.org/10.1016/ 0956-716X(95)00333-Q.

[61] M. Lifshitz, V.V. Slyozov, The kinetics of precipitation from supersaturated solid solutions, J. Phys. Chem. Solid. 19 (1961) 35-50, https://doi.org/10.1016/0022 3697(61)90054-3.

[62] C. Wagner, Theorie der Alterung von Niederschlaegen durch Umlosen (Ostwald Reifung), Phys. Chem. Chem. Phys. 65 (2010) 581-591, https://doi.org/10.1002/ bbpc.19610650704.

[63] W.A. Soffa, D.A. Laughlin, 8 - Diffusional phase transformations in the solid state, in: D.E. Laughlin, K. Hono (Eds.), Physical Metallurgy, 5 ed., Elsevier, Amsterdam, 2014, pp. 851-1020, https://doi.org/10.1016/B978-0-444-53770-6.00008-3.

[64] F. Abe, Coarsening behavior of lath and its effect on creep rates in tempered martensitic 9Cr-W steels, Mater. Sci. Eng., A 387-389 (2004) 565-569, https:// doi.org/10.1016/j.msea.2004.01.057.

[65] J.P. Sanhueza, D. Rojas, J. García, M.F. Melendrez, E. Toledo, C. Montalba, M. I. Alvarado, A.F. Jaramill, Computational modeling of the effect of B and W in the phase transformation of $\mathrm{M}_{23} \mathrm{C}_{6}$ carbides in 9 to 12 pct $\mathrm{Cr}$ martensitic/ferritic steels, Mater. Res. Express 6 (2019) 1165d3, https://doi.org/10.1088/2053-1591/ ab500c.

[66] C.R. Hutchinson, J.F. Nie, S. Gorsse, Modeling the precipitation processes and strengthening mechanisms in a Mg-Al-(Zn) AZ91 alloy, Metall. Mater. Trans. 36 (2005) 2093-2105, https://doi.org/10.1007/s11661-005-0330-x.

[67] M. Taneike, K. Sawada, F. Abe, Effect of carbon concentration on precipitation behavior of $\mathrm{M}_{23} \mathrm{C}_{6}$ carbides and $\mathrm{MX}$ carbonitrides in martensitic $9 \mathrm{Cr}$ steel during heat treatment, Metall. Mater. Trans. 35 (2004) 1255-1262, https://doi.org/ 10.1007/s11661-004-0299-x.

[68] W. Jung, S. Lee, S. Chung, Energetics for interfaces between group IV transition metal carbides and bcc iron, ISIJ Int. 48 (2008) 1280-1284, https://doi.org/ 10.2355/isijinternational.48.1280.

[69] Z.G. Yang, M. Enomoto, Discrete lattice plane analysis of Baker-Nutting related B1 compound/ferrite interfacial energy, Mater. Sci. Eng., A 332 (2002) 184-192, https://doi.org/10.1016/S0921-5093(01)01729-4.

[70] Y. Du, X. Li, X. Zhang, Y. Chung, D. Isheim, S. Vaynman, Design and characterization of a heat-resistant ferritic steel strengthened by MX precipitates, Metall. Mater. Trans. 51 (2020) 638-647, https://doi.org/10.1007/s11661-01905525-1. 